\title{
Avaliação eletrocardiográfica de recém-nascidos normais na primeira semana de vida
}

Tese apresentada à Faculdade de Medicina da Universidade de São Paulo para obtenção do título de Doutor em Ciências - versão corrigida. Versão original disponível na biblioteca da Faculdade de Medicina da Universidade de São Paulo e na Biblioteca Digital de Teses e Dissertações da Universidade de São Paulo

Programa de Cardiologia

Orientador: Prof. Dr. Carlos Alberto

Pastore

Coorientadora: Profa. Dra. Vera Lúcia Jornada Krebs

\section{São Paulo}




\section{Dados Internacionais de Catalogaçăo na Publicaçăo (CIP)}

Preparada pela Biblioteca da

Faculdade de Medicina da Universidade de Săo Paulo

Creproduçāo autorizada pelo autor

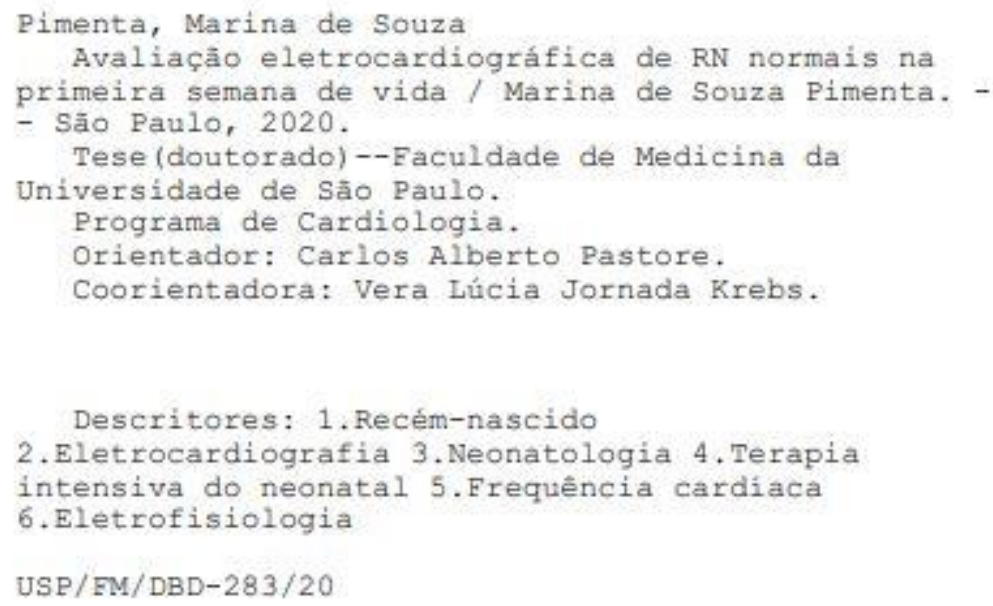

Responsável: Erinalva da Conceiçāo Batista, CRB-8 6755 


\section{AGRADECIMENTOS}

Agradeço à minha mãe, pela sua dedicação total e integral a nós, e ao meu pai, por despertar em mim a fascinação pela medicina e pela ciência. Agradeço ao meu marido Bruno, por acreditar em mim, mesmo quando eu pensava não ser possível.

Agradeço à Dra. Vera Krebs, pelo apoio, ajuda e incentivo desde os tempos de iniciação científica, tendo estimulado e acompanhado toda a minha formação como aluna, residente, doutoranda e médica.

Agradeço ao Dr. Nelson Samesima e ao Dr. Carlos Alberto Pastore, por toda a paciência, estímulo, e orientação. Agradeço à Márcia Dancini, por toda a ajuda e disponibilidade nos últimos anos. Agradeço também a toda a equipe da eletrocardiografia do InCor, pelo carinho e confiança ao terem adotado uma pediatra como uma de vocês.

Por fim, dedico este ao meu filho Guilherme, que tornou tudo deliciosamente mais difícil. 


\section{NORMATIZAÇÃO ADOTADA}

Esta tese está de acordo com as seguintes normas, em vigor no momento desta publicação:

- Referências adaptadas de International Committee of Medical Journals Editors (Vancouver). Universidade de São Paulo. Faculdade de Medicina. Divisão de Biblioteca e Documentação. Guia de apresentação de dissertações, teses e monografias. Elaborado por Anneliese Carneiro da Cunha, Maria Julia de A. L. Freddi, Maria F. Crestana, Marinalva de Souza Aragão, Suely Campos Cardoso, Valéria Vilhena. 3a ed. São Paulo: Divisão de Biblioteca e Documentação; 2011.

- Abreviaturas dos títulos dos periódicos de acordo com a List of Journals Indexed in Index Medicus. 


\section{SUMÁRIO}

Resumo

Summary

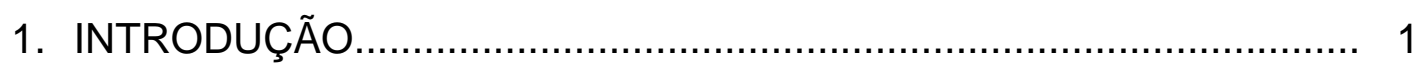

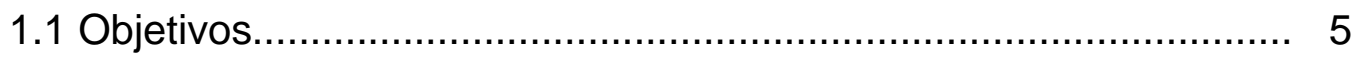

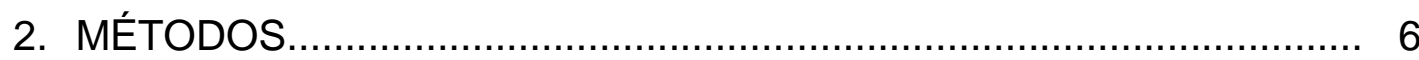

2.1 Delineamento do estudo.......................................................... 6

2.2 População................................................................................... 7

2.2.1 Critérios de inclusão.......................................................... 9

2.2.2 Critérios de exclusão......................................................... 10

2.3 Eletrocardiograma................................................................. 11

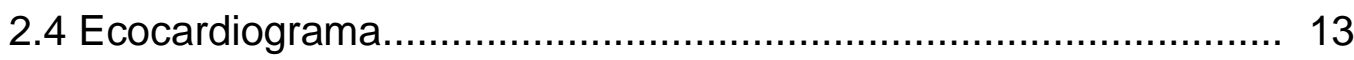

2.5 Variáveis eletrocardiográficas analisadas...................................... 14

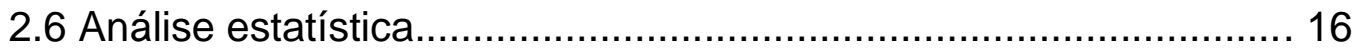

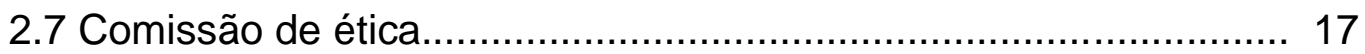

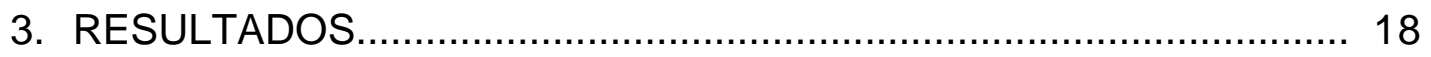

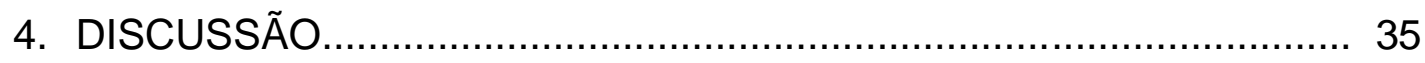

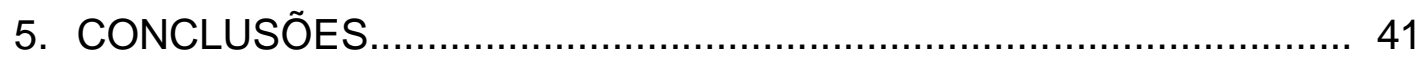

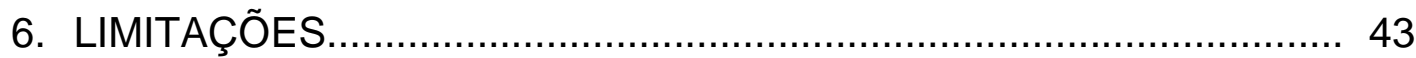

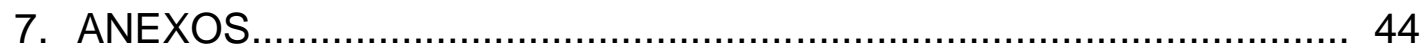

8. REFERÊNCIAS BIBLIOGRÁFICAS................................................. 62 


\section{RESUMO}

Pimenta MS. Avaliação eletrocardiográfica de $R N$ normais na primeira semana de vida [tese]. São Paulo: Faculdade de Medicina, Universidade de São Paulo; 2020.

O período neonatal é marcado por grandes alterações no sistema cardiovascular, principalmente na primeira semana de vida. Diferentemente da população adulta, os estudos sobre eletrocardiograma (ECG) no período neonatal são escassos. Este é o primeiro trabalho correlacionando achados eletrocardiográficos com ecocardiograma normal em uma população de recém nascidos (RN) e o primeiro trabalho que estuda ECG em neonatos na população brasileira. O objetivo deste estudo é analisar os padrões eletrocardiográficos de uma população de $\mathrm{RN}$ a termo, comprovadamente sem alterações morfológicas e funcionais cardíacas, em três grupos etários (até 24 horas de vida, entre 25 e 72 horas de vida e entre 73 e 168 horas de vida), comparando os dados obtidos com os disponíveis na literatura. Foram estudados de forma prospectiva $94 \mathrm{RN}$. Dentre os três grupos etários estudados, houve diferenças significativas na orientação das ondas $T$ nas derivações V1, V2, V3 e V4. Quando comparados com os dados da literatura, houve diferença estatística na maior parte dos parâmetros eletrocardiográficos estudados.

Descritores: Recém-nascido; Eletrocardiografia; Neonatologia; Terapia intensiva neonatal; Frequência cardíaca; Eletrofisiologia. 


\begin{abstract}
Pimenta MS. Electrocardiographic evaluation of normal newborns in the first week of life [thesis]. São Paulo: "Faculdade de Medicina, Universidade de São Paulo"; 2020.

The neonatal period is marked by major changes in the cardiovascular system, especially in the first week of life. Unlike the adult population, studies about electrocardiogram (ECG) in the neonatal period are scarce. This is the first study correlating electrocardiographic findings in a population of newborns (NB) with normal structural and functional heart and the first that studies ECG in neonates in the Brazilian population. The aim of this study is to analyze the electrocardiographic patterns of a population of full-term NB, proven to have no cardiac morphological and functional anomalies, in three age groups (up to 24 hours of life, between 25 and 72 hours of life and between 73 and 168 hours of life), correlating our findings with current literature. Were prospectively studied 94 NB. Among the three age groups studied, there were significant differences in the direction of $\mathrm{T}$ waves in leads V1, V2, V3 and V4. Comparing our results with the literature, there were significant differences in most electrocardiographic parameters.
\end{abstract}

Descriptors: Infant, newborn; Electrocardiography; Neonatology; Intensive care, neonatal; Heart rate; Electrophysiology. 


\section{INTRODUÇÃO}

O período neonatal é marcado por grandes alterações hemodinâmicas e anatômicas no sistema cardiovascular, principalmente na primeira semana de vida, quando ocorre a transição da circulação fetal para a neonatal ${ }^{1,2}$. Durante o período fetal, o sangue venoso é transportado à placenta pelas duas artérias umbilicais. Na placenta, o sangue é oxigenado e enriquecido com nutrientes provenientes da mãe e transportado novamente ao feto com sangue arterial pela veia umbilical. Aproximadamente $50-60 \%$ do sangue arterial transportado pela veia umbilical passa pelo fígado através do ducto venoso e é encaminhado ao átrio direito pela veia cava inferior. A maior parte deste sangue é direcionada pela válvula de Eustáquio e passa pelo forame oval, seguindo para o átrio esquerdo, ventrículo esquerdo, aorta e toda a circulação sistêmica, incluindo o miocárdio e cérebro. Desta forma, é garantido que órgãos nobres recebam o sangue com maior quantidade de oxigênio e nutrientes. O sangue venoso que chega ao átrio direito pela veia cava superior segue ao ventrículo direito e artérias pulmonares. Diante da alta resistência da circulação pulmonar presente intraútero, aproximadamente $88 \%$ deste sangue segue pelo canal arterial para a aorta, seguindo para a metade inferior do corpo, que recebe o sangue menos oxigenado. Deste modo, durante o período fetal, o átrio e ventrículo direitos são predominantes e hipertróficos em relação às câmaras esquerdas.

Após o clampeamento do cordão umbilical e a primeira respiração, ocorre uma drástica diminuição da resistência vascular pulmonar e aumento da 
resistência vascular sistêmica. Há um aumento no fluxo sanguíneo pulmonar e, consequentemente, aumento do retorno venoso para o átrio esquerdo e diminuição do retorno venoso para o átrio direito, levando à oclusão funcional do forame oval. $\mathrm{O}$ ducto venoso e o canal arterial também se fecham nas primeiras horas após o nascimento e o maior crescimento e predomínio ventricular se altera do ventrículo direito para o esquerdo ${ }^{1,3}$. Essas alterações podem ser evidenciadas por parâmetros clínicos, como frequência cardíaca (FC), saturometria, padrão respiratório e ausculta cardíaca, e por exames complementares, como ecocardiograma (ECO), lactato e bicarbonato séricos, entre outros.

O eletrocardiograma (ECG), desenvolvido em 1902 pelo fisiologista holandês Willem Einthoven, é frequentemente utilizado em unidades de terapia intensiva neonatal para ajudar a diagnosticar distúrbios do ritmo e condições clínicas. Diferentemente de outros exames e métodos diagnósticos, o ECG é um teste simples e de baixo custo, amplamente disponível e de fácil execução, sendo muitas vezes realizado e interpretado pelo médico plantonista em caráter de urgência.

Diferentemente da população adulta, os estudos sobre ECG no período neonatal são escassos, com publicações antigas e sem incluir neonatos brasileiros, podendo não corresponder à realidade brasileira atual. ${ }^{1,2,4} \mathrm{Em}$ 1971, Hastreiter et Abella ${ }^{1}$ publicaram um estudo de revisão visando descrever o ECG normal em recém-nascidos (RN), dividindo-os em três grupos: 0-24 hora, 1-7 dias e 7-30 dias de vida. Publicado em 1979, o estudo de Davignon et $a^{2}{ }^{2}$ é, até hoje, o trabalho mais completo realizado sobre o tema, sendo analisada uma coorte de 2.141 crianças canadenses, dentre as quais $668 \mathrm{RN}$, 
sendo 549 nos primeiros 7 dias de vida. Este trabalho tem sido utilizado até 0 momento como referência para avaliar $\mathrm{RN}$. Rijnbeek et $\mathrm{al}^{5}$ realizaram na Holanda, no ano de 2001, um estudo semelhante, incluindo 1.912 pacientes. Entretanto, apenas 44 eram neonatos.

Na população brasileira, Palhares et al $^{6}$ analisaram o ECG de 486.014 indivíduos hígidos com idade superior a um ano em um serviço de atenção primária. Na literatura consultada, até outubro de 2020, não foram encontradas publicações sobre o ECG no período neonatal na população brasileira.

Esta situação é ainda mais crítica quando se pesquisam as características eletrocardiográficas de $\mathrm{RN}$ com maior risco para cardiopatia estrutural $^{7}$, tais como filhos de mães diabéticas ${ }^{7,8}$, parentes de primeiro grau com cardiopatia congênita, presença de malformações extracardíacas e sopro audível após 48 horas de vida9 ${ }^{9}$. No ano de 2016, houve 2.857 .800 nascidos vivos no Brasil, 2.462 destes com cardiopatia congênita, correspondendo a 0,08\% dos nascidos vivos e a $9,4 \%$ de todos os $\mathrm{RN}$ com malformações congênitas. No Estado de São Paulo, referência nacional para nascimento e tratamento destas crianças, anomalias estruturais cardíacas corresponderam a $17,5 \%$ dos nascimentos com malformações congênitas. Esta é a terceira anomalia congênita mais comum no país, após malformações osteomusculares e do sistema nervoso central $^{10}$. No Hospital das Clínicas da Universidade de São Paulo, entre os anos de 2007-2008, aproximadamente 6\% dos nascidos vivos eram portadores de malformações congênitas, sendo as cardiopatias congênitas a terceira malformação mais comum ${ }^{11}$. Sabe-se que filhos de mães com diabetes mellitus (DM), doença cada vez mais prevalente nas gestantes, apresentam incidência maior de cardiopatia congênita (em torno de $30 \%$ ), 
principalmente hipertrofia septal assimétrica, hipertrofia ventricular e disfunção diastólica ${ }^{8}$. Em um dos poucos estudos disponíveis, Page et al ${ }^{12}$ analisaram o ECG de 21 RN filhos de mães diabéticas. Contudo, trata-se de uma análise de 1960, em uma coorte pequena e sem correlação com características estruturais cardíacas, sendo os dados insuficientes para aplicabilidade clínica.

Assim, a escassez de conhecimentos sólidos sobre os padrões e alterações eletrocardiográficas em $\mathrm{RN}$ com alta prevalência de cardiopatia estrutural motivou o desenvolvimento deste projeto. Este é o primeiro trabalho correlacionando achados eletrocardiográficos com ECO normal em uma coorte de RN e o primeiro trabalho que estuda ECG em neonatos na população brasileira. 


\section{1. OBJETIVOS}

Primário

Analisar os padrões eletrocardiográficos de uma população de $\mathrm{RN}$ a termo, comprovadamente sem alterações morfológicas e funcionais cardíacas, em três grupos etários (até 24 horas, entre 25 e 72 horas e entre 73 e 168 horas de vida), comparando os dados obtidos com os disponíveis na literatura.

\section{$\underline{\text { Secundários }}$}

Caracterizar a influência da classificação do peso em relação à idade gestacional (IG) - pequeno, adequado ou grande - no padrão eletrocardiográfico.

Avaliar a influência de morbidades maternas: DM e hipertensão arterial (HA), no padrão eletrocardiográfico do recém-nascido. 


\section{MÉTODOS}

\subsection{Delineamento do estudo}

Trata-se de estudo transversal prospectivo com RN a termo, nascidos no Centro Obstétrico e admitidos no Centro Neonatal do Instituto da Criança do Hospital das Clínicas da Faculdade de Medicina da Universidade de São Paulo (HC-FMUSP). A coleta de dados foi realizada entre 16 de agosto de 2016 e 30 de julho de 2018. 


\subsection{População}

Foram incluídos no estudo RN a termo (entre 37 e 41 6/7 semanas de IG), que tenham realizado ECO na rotina da internação neonatal e que apresentaram ECO sem malformação cardíaca, conforme fluxograma a seguir:

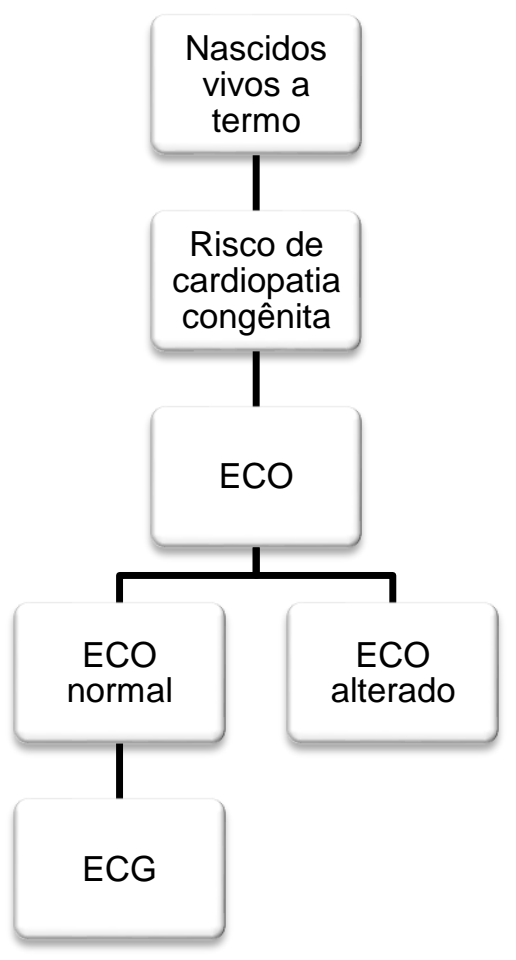

O ECO é realizado como rotina em $\mathrm{RN}$ com risco de cardiopatia congênita, tais como:

- filhos de mães diabéticas que utilizaram insulina durante a gestação;

- com malformações extracardíacas conhecidas no período perinatal;

- com sopro cardíaco audível após 48 horas de vida; 
- com parentes de $1^{\circ}$ grau (pais/irmãos) portadores de cardiopatia congênita conhecida;

- com teste de oximetria alterado;

- com ECO fetal alterado. 


\subsubsection{Critérios de Inclusão}

1. RN a termo, com risco de cardiopatia congênita e ECO normal e evolução cardiovascular normal durante a internação hospitalar.

2. RN com alterações anatômicas menores, sem relevância clínica para a faixa etária e evolução cardiovascular normal durante a internação hospitalar, tais como:

- estenose relativa de artérias pulmonares;

- forame oval patente;

- canal arterial patente sem repercussão hemodinâmica, menor que $4 \mathrm{~mm}$;

- comunicação interatrial tipo Ostium Secundum sem repercussão hemodinâmica, menor que $4 \mathrm{~mm}$;

- comunicação interventricular muscular sem repercussão hemodinâmica, menor que $2 \mathrm{~mm}$;

- persistência do padrão fetal. 


\subsubsection{Critérios de exclusão}

1. RN com malformações maiores extracardíacas, tal como malformações do sistema nervoso central (hidrocefalia, Síndrome de Dandy-Walker e mielomeningocele).

2. RN com síndromes genéticas, como trissomias cromossômicas (Síndrome de Down, Síndrome de Edwards e Síndrome de Patau) e aneuploidias (Síndrome de Turner) ou síndromes genéticas a esclarecer (suspeita clínica). 


\section{$\underline{2.3 \text { Eletrocardiograma }}$}

Os eletrocardiogramas de 12 derivações (simultâneas a cada 3 derivações) foram realizados todos pela médica pesquisadora após ser devidamente habilitada e treinada, durante a internação hospitalar dos neonatos.

Foi utilizado o aparelho da Philips PageWriter TC20@ (Koninklijke Philips, N.V). Os eletrodos pediátricos de gel foram posicionados sobre os ombros direito e esquerdo, sobre as espinhas ilíacas direita e esquerda, e V1V6 conforme o habitual ${ }^{13}$. O posicionamento sobre os ombros e as espinhas ilíacas foi preferível ao invés de braços e pernas devido à mobilidade excessiva dos $\mathrm{RN}$ e à possibilidade de obtenção de um ECG com menos inteferência ${ }^{14}$ (figura 1). 


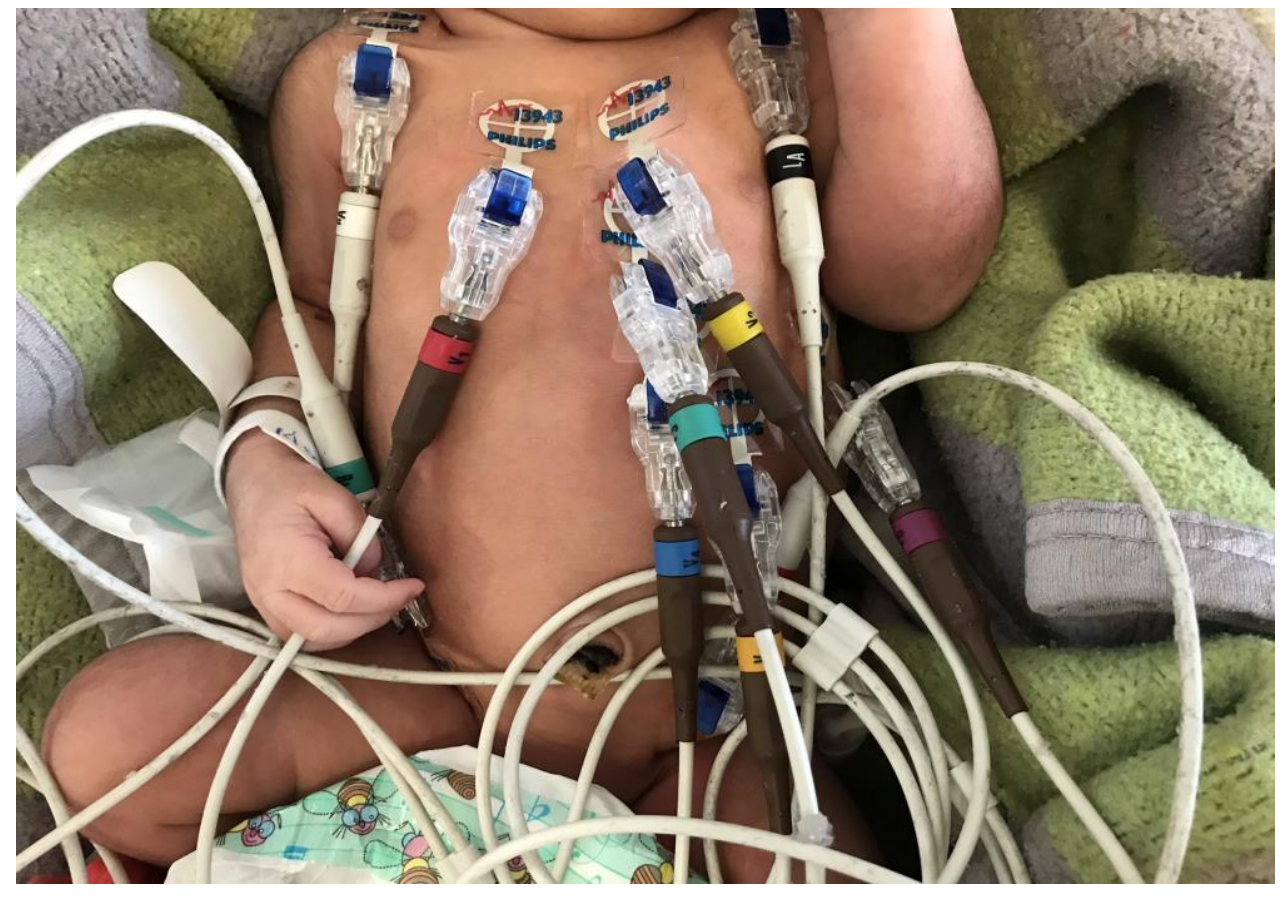

Figura 1: Posicionamento de eletrodos para a realização de ECG em RN. 


\section{$\underline{2.4 \text { Ecocardiograma }}$}

Um ECO bidimensional com Doppler e mapeamento de fluxo em cores detalhado foi realizado em todos os pacientes por ecocardiografista pediátrico com experiência em neonatologia. Utilizou-se o equipamento Philips CX50 (Koninklijke Philips N.V.) e os transdutores multifrequência S8-3 e S12-4. As medidas ecocardiográficas foram realizadas segundo os critérios da American Society of Echocardiography (ASE) ${ }^{15}$. As medidas do septo interventricular, do átrio esquerdo, da parede posterior e diâmetro diastólico do ventrículo esquerdo, e do ventrículo direito foram realizadas pelo modo M. A fração de ejeção foi obtida pelo método de Teichholz e considerada normal quando acima de $55 \%$. As medidas encontradas foram ajustadas pela superfície corpórea segundo o z-score definido por Kampmann et al $^{16}$ e consideradas normais quando entre $-2 \mathrm{e}+2$. 


\section{$\underline{2.5 \text { Variáveis eletrocardiográficas analisadas }}$}

Os seguintes parâmetros foram medidos de forma manual pela pesquisadora e analisados de acordo com os grupos etários:

- FC em batimentos por minuto - medida de forma automática pelo equipamento e confirmada manualmente pela pesquisadora;

- eixo QRS em graus;

- amplitude em milivolts e duração em milissegundos da onda P na derivação DII e V1;

- duração do intervalo PR em DIl em milissegundos;

- duração do intervalo QT em milissegundos e do intervalo QT corrigido (QTc) através da fórmula de Bazett em V2 (derivação escolhida por ser a derivação em que a onda T é melhor definida para mensuração);

- amplitude em milivolts e duração do QRS em milissegundos em todas as 12 derivações;

- sentido da onda T em todas as 12 derivações;

- relação R/S em V1, V5 e V6.

Também foi analisada a influência de três condições sobre os parâmetros eletrocardiográficos listados:

- tamanho dos RN: Pequeno para Idade Gestacional (PIG), Adequado para Idade Gestacional (AIG) e Grande para Idade Gestacional (GIG); 
- mãe com e sem DM: diabetes mellitus tipo 1 (DM1), diabetes mellitus tipo 2 (DM2) e diabetes mellitus gestacional (DMG);

- mãe com e sem HA: hipertensa crônica (HAC), doença hipertensiva específica da gravidez (DHEG) ou hipertensão arterial prévia com doença hipertensiva específica da gravidez superajuntada $(\mathrm{HAC}+\mathrm{DHEG})$. 


\subsection{Análise estatística}

Foram descritas as características qualitativas maternas e dos $\mathrm{RN}$ com uso de frequências absolutas e relativas. As características quantitativas foram descritas com uso de medidas resumo (média, desvio padrão, mediana, mínimo e máximo) para todos os avaliados ${ }^{17}$.

Os parâmetros do ECG foram descritos segundo as doenças maternas e características do recém-nascido com o uso de medidas resumo. Os parâmetros entre as categorias de interesse foram comparados com uso de análises de variância (ANOVA), seguidas de comparações múltiplas de Bonferroni quando significativas, para identificar entre quais categorias houve diferença ${ }^{18}$.

Os parâmetros encontrados foram descritos em curvas de percentis e comparados com os valores de normalidade segundo as faixas etárias conforme as Diretrizes da Sociedade Brasileira de Cardiologia ${ }^{4}$ e os percentis apresentados no artigo de Davignon et al ${ }^{2}$.

As análises foram realizadas com uso do software IBM-SPSS for Windows versão 22.0 e tabulados com uso do software Microsoft-Excel 2010. Foi considerado significante $o$ valor de $p \leq 0,05$. 


\subsection{Comissão de Ética}

O projeto foi aprovado pela Comissão de Ética do Hospital das Clínicas da Faculdade de Medicina da Universidade de São Paulo (CAPPesq/HCFMUSP). Registro on-line no 14.742, SDC/COP/059-17. 


\section{RESULTADOS}

No período do estudo houve 2.883 nascidos vivos na Unidade Neonatal. Destes, 1.916 foram $\mathrm{RN}$ a termo. Foram realizados 753 ecocardiogramas, sendo 310 destes RN a termo. Dentre os 310 ecocardiogramas de $\mathrm{RN}$ a termo, 191 não apresentavam alterações anatômicas com relevância clínica.

Foram realizados eletrocardiogramas de $113 \mathrm{RN}$. A casuística final do presente estudo foi composta por 94 pacientes, sendo excluídos 19 RN por apresentarem malformações maiores extracardíacas, principalmente anomalias do sistema nervoso central ou síndromes genéticas, conforme descrito nos critérios de exclusão.

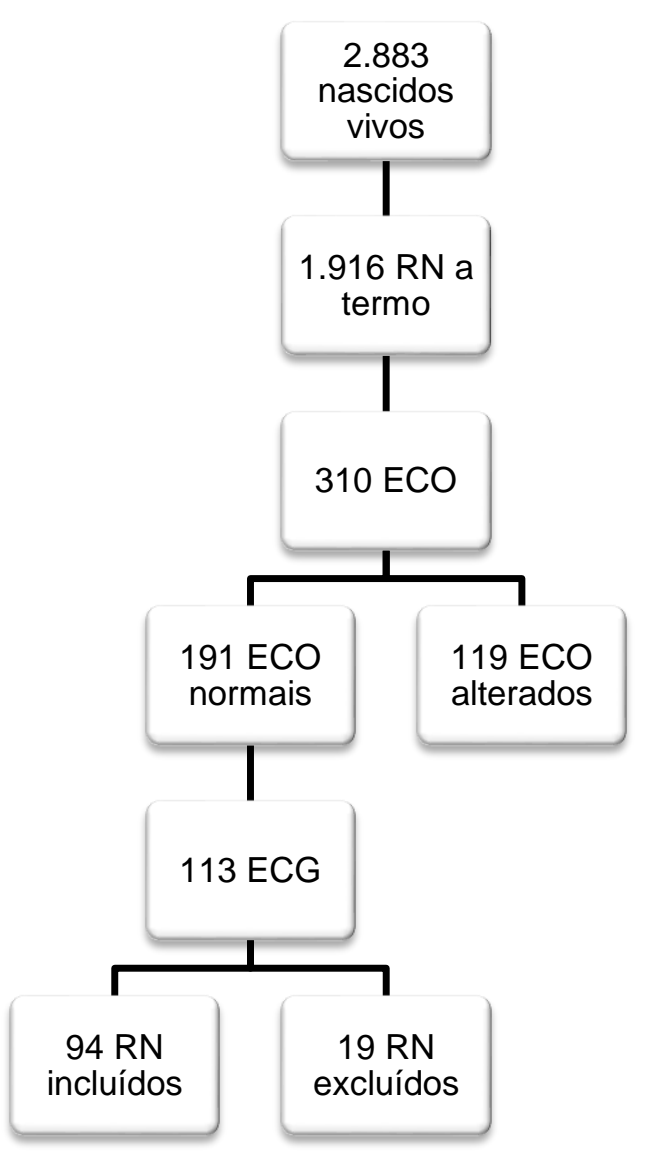


As características clínicas dos RN estão apresentadas na tabela 1.

Tabela 1. Características clínicas de $94 \mathrm{RN}$ estudados.

\begin{tabular}{|c|c|}
\hline Variável & Descrição (n=94) \\
\hline \multicolumn{2}{|l|}{ Grupo HV, n(\%) } \\
\hline$\leq 24 \mathrm{hv}$ & $11(11,7)$ \\
\hline 25-72hv & $46(48,9)$ \\
\hline 73-168hv & $37(39,4)$ \\
\hline \multicolumn{2}{|l|}{ Class. RN, n(\%) } \\
\hline PIG & $9(9,6)$ \\
\hline AIG & $77(81,9)$ \\
\hline GIG & $8(8,5)$ \\
\hline \multicolumn{2}{|l|}{ Parto, n(\%) } \\
\hline Normal & $31(33,0)$ \\
\hline Fórcipe & $9(9,6)$ \\
\hline Cesárea & $54(57,4)$ \\
\hline \multicolumn{2}{|l|}{ Gênero, n(\%) } \\
\hline Feminino & $53(56,4)$ \\
\hline Masculino & $40(42,6)$ \\
\hline Indeterminado & $1(1,0)$ \\
\hline \multicolumn{2}{|l|}{ IG (semanas) } \\
\hline média \pm DP & $38,6 \pm 1,1$ \\
\hline $\begin{array}{l}\text { Peso de nascimento }(\mathbf{g}) \\
\text { média }+\mathrm{DP}\end{array}$ & $3184+551$ \\
\hline
\end{tabular}

HV = horas de vida; Class. = classificação; $\mathbf{R N}=$ recém-nascido; $\mathbf{I G}=$ idade gestacional; PIG = pequeno para idade gestacional; $\mathbf{A I G}=$ adequado para idade gestacional; $\mathbf{G I G}$ = grande para idade gestacional; $\mathbf{D P}=$ desvio padrão. 
Quando separados por grupos etários ( $\leq 24 \mathrm{hv}, 25-72 \mathrm{hv}$ e 73-168hv), foram encontradas, quanto aos parâmetros eletrocardiográficos básicos, as seguintes médias, respectivamente:

- $\mathrm{FC} 122 \times 122 \times 131 \mathrm{bpm}(p=0,051)$;

- $\quad$ amplitude da onda P em DII 0,11 x 0,13 x 0,13mV $(p=0,231)$;

- $\quad$ intervalo PR em DII 92 × 99 × 98ms $(p=0,483)$;

- $\quad$ intervalo QT em V2 $301 \times 293$ x 274ms $(p=0,112)$;

- $\quad$ eixo QRS $126 \times 128 \times 134^{\circ}$;

- duração do complexo QRS em V5 40 x 44 x 46ms ( $p=0,143)$.

Além da tendência de maior FC entre 73-168hv, a análise estatística não mostrou diferença significante nos demais parâmetros acima.

Quanto às amplitudes da onda $Q$, foram encontradas nas seguintes derivações, nos grupos $\leq 24 \mathrm{hv}, 25-72 \mathrm{hv}$ e 73-168hv, respectivamente, as seguintes médias:

- DIII 0,41 x 0,34 x 0,36mV;

- $\quad \operatorname{aVF} 0,30 \times 0,23 \times 0,27 \mathrm{mV}$;

- V5 0,10 x 0,04 x 0,10mV;

- V6 0,13 x 0,06 x 0,12mV.

Quanto às amplitudes da onda $\mathrm{R}$, foram encontradas nas seguintes derivações, nos grupos $\leq 24 \mathrm{hv}, 25-72 \mathrm{hv}$ e 73-168hv, respectivamente, as seguintes médias:

- $\operatorname{aVR} 0,33 \times 0,33 \times 0,25 \mathrm{mV}$;

- $\quad \mathrm{V} 11,25 \times 1,13 \times 1,13 \mathrm{mV}$;

- $\quad \mathrm{V} 21,35 \times 1,19 \times 1,27 \mathrm{mV}$; 
- V4 1,74 x 1,57 x 1,57mV;

- V5 $1,41 \times 1,30 \times 1,29 \mathrm{mV}$;

- V6 $1,26 \times 1,17 \times 1,14 \mathrm{mV}$.

Quanto às amplitudes da onda S, foram encontradas nas seguintes derivações, nos grupos $\leq 24 \mathrm{hv}, 25-72 \mathrm{hv}$ e 73-168hv, respectivamente, as seguintes médias:

- $\quad \mathrm{V} 11,00 \times 0,97 \times 0,67 \mathrm{mV}$;

- $\quad$ V2 1,40 x 1,34 x 1,08mV;

- V4 1,21 x 0,97 x 0,88mV;

- $\quad \mathrm{V} 50,77 \times 0,75 \times 0,62 \mathrm{mV}$;

- $\quad$ V6 0,59 x 0,67 x 0,52mV.

A relação entre as ondas $R$ e $S$ em três derivações nos três grupos etários ( $\leq 24 \mathrm{hv}, 25-72 \mathrm{hv}$ e 73-168hv), apresentou as seguintes médias, respectivamente:

- $\mathrm{R} / \mathrm{S}$ em V1 $0,14 \times 0,21 \times 0,24(p=0,344)$;

- $\mathrm{R} / \mathrm{S}$ em V5 0,53 x 0,30 x 0,34 $(p=0,380)$;

- $\mathrm{R} / \mathrm{S}$ em V6: $0,53 \times 0,33 \times 0,32(p=0,295)$.

Outras análises realizadas foram:

- $\mathrm{R}+\mathrm{S}$ em V2 2,75 x 2,53 x 2,36mV;

- $\mathrm{R}+\mathrm{S}$ em V4 2,95 x 2,54 x 2,45mV;

- $\mathrm{S}$ em V2 + R em V5 2,81 x 2,64 x 2,38mV;

- $\mathrm{S}$ em V1 + R em V6 2,25 x 2,14 x 1,81mV.

Os percentis 5, 50 e 95 das variáveis descritas acima estão apresentados na tabela 2. Todos os percentis calculados das variáveis 
estudadas $(2,5,25,50,75,95$ e 98), segundo os grupos etários, estão expostos nos anexos $\mathrm{A}$ a $\mathrm{Ag}$. 


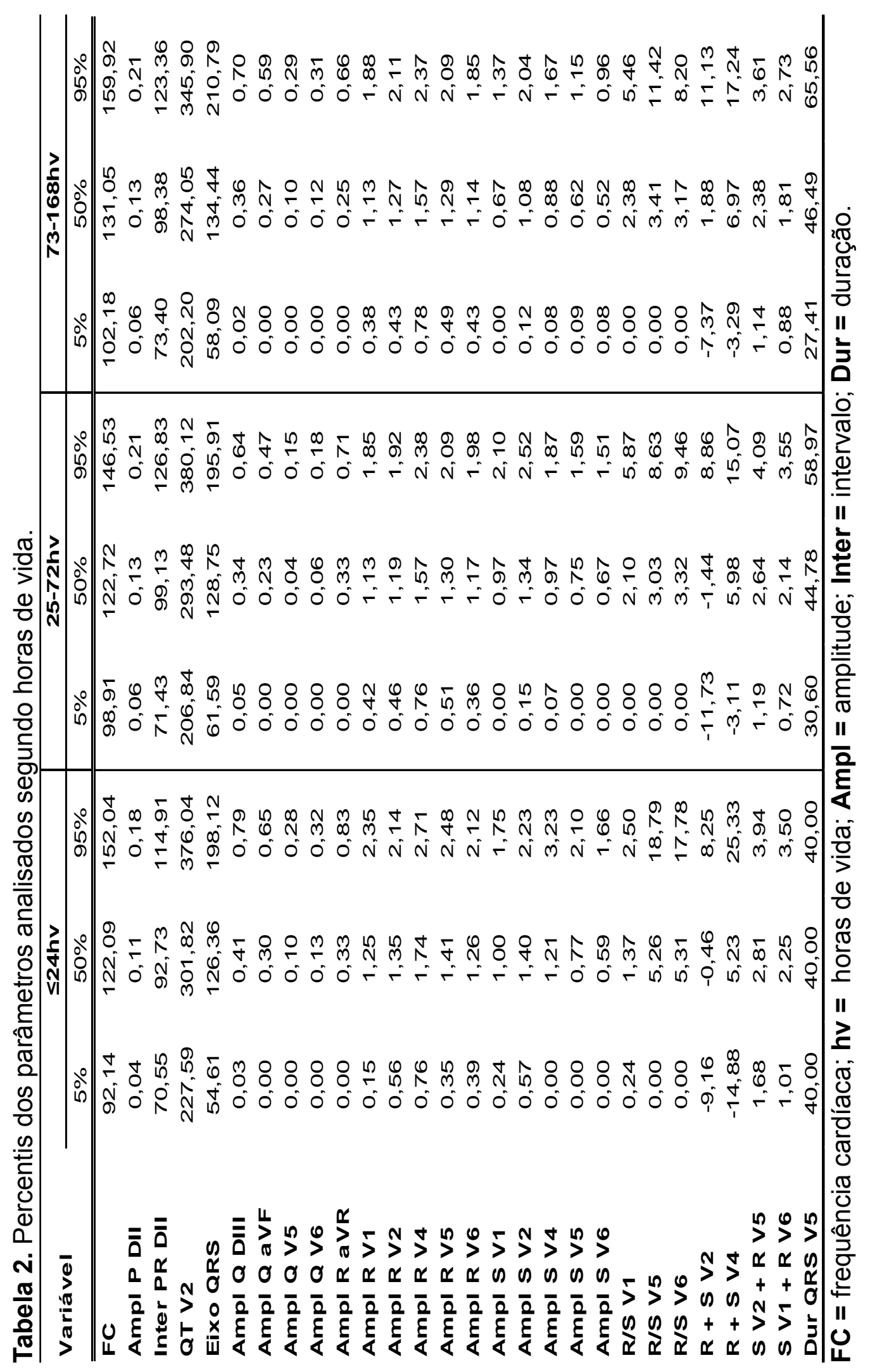


Ao analisar a faixa etária da população estudada (tabela 3) observou-se que os RN com 24 horas de vida ou menos apresentaram proporção significativamente maior de ondas $\mathrm{T}$ positivas em relação aos $\mathrm{RN}$ dos grupos mais velhos (25-72h e 73-168h), respectivamente, nas derivações V1 (45,5\% $\times 17,4 \% \times 5,4 \% ; p=0,042), \mathrm{V} 2(54,5 \% \times 15,2 \% \times 10,8 \% ; p=0,019), \mathrm{V} 3(72,7 \% \times$ $26,1 \% \times 13,5 \% ; p=0,008)$ e V4 $(90,9 \% \times 58,7 \% \times 35,1 \% ; p=0,005)$. 
Tabela 3. Parâmetros eletrocardiográficos segundo faixa etária do $\mathrm{RN}$ e resultado dos testes comparativos.

\begin{tabular}{|c|c|c|c|c|}
\hline \multirow{2}{*}{ Variável } & \multicolumn{3}{|c|}{ Horas de vida } & \multirow{2}{*}{$p$} \\
\hline & $\leq 24 \mathrm{hv}$ & 25-72hv & 73-168hv & \\
\hline Orientação T V1, n (\%) & & & & 0,042 \\
\hline Positivo & $5(45,5)$ & $8(17,4)$ & $2(5,4)$ & \\
\hline Negativo & $3(27,3)$ & $23(50,0)$ & $23(62,2)$ & \\
\hline Minus-plus & $3(27,3)$ & $15(32,6)$ & $12(32,4)$ & \\
\hline Orientação T V2, n (\%) & & & & 0,019 \\
\hline Positivo & $6(54,5)$ & $7(15,2)$ & $4(10,8)$ & \\
\hline Negativo & $4(36,4)$ & $21(45,7)$ & $23(62,2)$ & \\
\hline Minus-plus & $1(9,1)$ & $18(39,1)$ & $10(27,0)$ & \\
\hline Orientação T V3, n (\%) & & & & 0,008 \\
\hline Positivo & $8(72,7)$ & $12(26,1)$ & $5(13,5)$ & \\
\hline Negativo & $2(18,2)$ & $15(32,6)$ & $20(54,1)$ & \\
\hline Plus-minus & $0(0,0)$ & $1(2,2)$ & $0(0,0)$ & \\
\hline Minus-plus & $1(9,1)$ & $18(39,1)$ & $12(32,4)$ & \\
\hline Orientação T V4, n (\%) & & & & 0,005 \\
\hline Positivo & $10(90,9)$ & $27(58,7)$ & $13(35,1)$ & \\
\hline Negativo & $1(9,1)$ & $10(21,7)$ & $21(56,8)$ & \\
\hline Indeterminado & $0(0,0)$ & $2(4,3)$ & $0(0,0)$ & \\
\hline Plus-minus & $0(0,0)$ & $1(2,2)$ & $1(2,7)$ & \\
\hline Minus-plus & $0(0,0)$ & $6(13,0)$ & $2(5,4)$ & \\
\hline Orientação T V5, n (\%) & & & & 0,486 \\
\hline Positivo & $10(90,9)$ & $34(73,9)$ & $22(59,5)$ & \\
\hline Negativo & $1(9,1)$ & $8(17,4)$ & $12(32,4)$ & \\
\hline Indeterminado & $0(0,0)$ & $1(2,2)$ & $1(2,7)$ & \\
\hline Plus-minus & $0(0,0)$ & $2(4,3)$ & $2(5,4)$ & \\
\hline Minus-plus & $0(0,0)$ & $1(2,2)$ & $0(0,0)$ & \\
\hline Orientação T V6, n (\%) & & & & 0,624 \\
\hline Positivo & $9(81,8)$ & $36(78,3)$ & $26(70,3)$ & \\
\hline Negativo & $2(18,2)$ & $6(13,0)$ & $9(24,3)$ & \\
\hline Indeterminado & $0(0,0)$ & $1(2,2)$ & $0(0,0)$ & \\
\hline Plus-minus & $0(0,0)$ & $3(6,5)$ & $2(5,4)$ & \\
\hline Minus-plus & $0(0,0)$ & $0(0,0)$ & $0(0,0)$ & \\
\hline
\end{tabular}

HV $=$ horas de vida; $\mathbf{A m p l}=$ amplitude. 
Ao comparar os valores encontrados com as Diretrizes da Sociedade Brasileira de Cardiologia ${ }^{4}$ (tabela 4), observou-se que houve significativa diferença estatística na maioria dos parâmetros analisados. Todos os parâmetros apresentaram diferença significante, com exceção de:

- $\mathrm{R} / \mathrm{S}$ em $\mathrm{V} 1$ no grupo $\leq 24 \mathrm{hv}$;

- $\mathrm{R} / \mathrm{S}$ em V6 no grupo $\leq 24 \mathrm{hv}$;

- amplitude da onda R em V6 no grupo 25-72hv.

No grupo 73-168 horas de vida, nenhum parâmetro foi semelhante. 


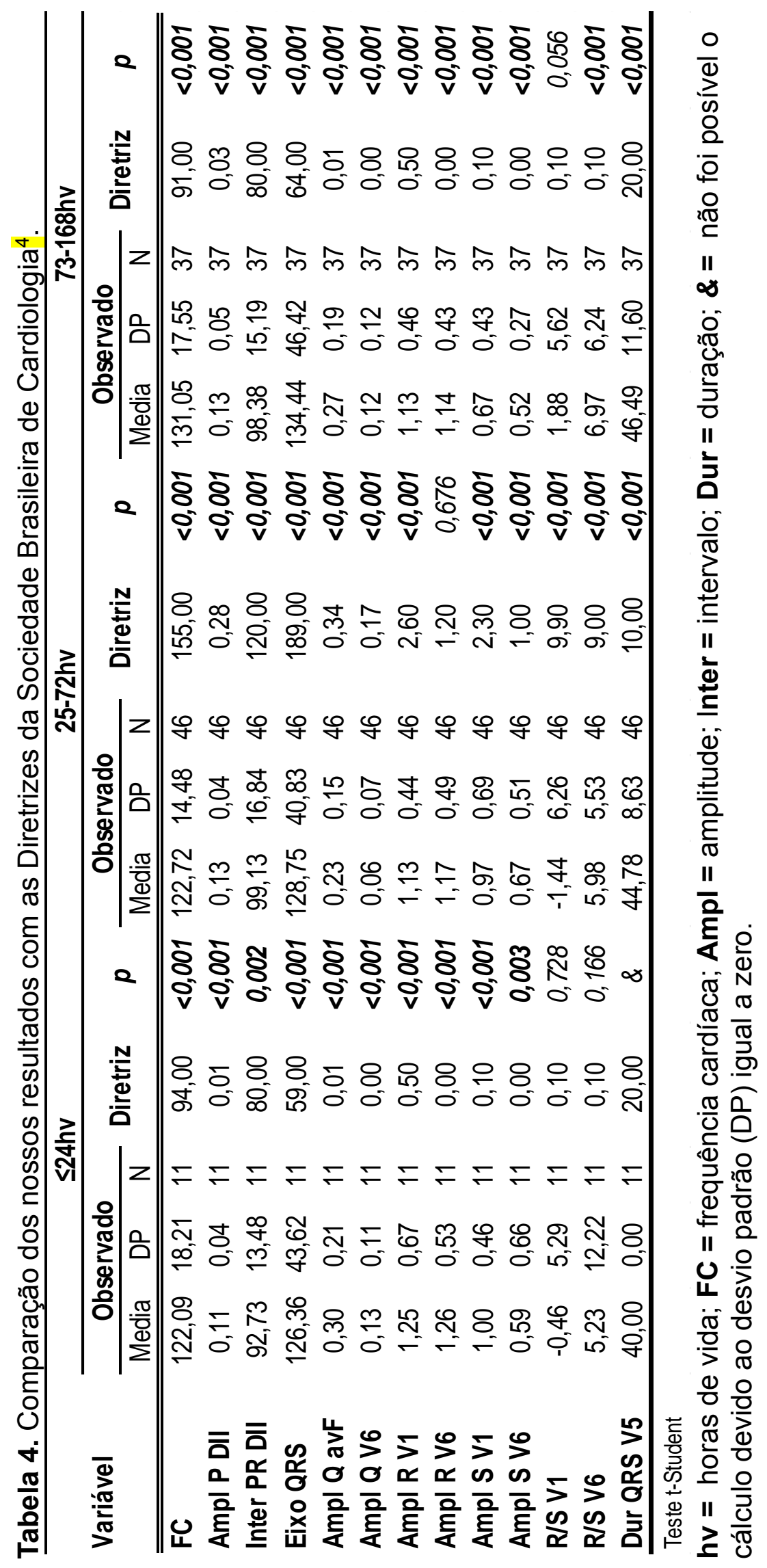


Ao compararmos os valores encontrados em nossa análise com os valores estimados extraídos do estudo de Davignon ${ }^{2}$ (tabela 5), notamos diferenças estatisticamente significantes em diversos parâmetros em todas as faixas etárias ( $\leq 24 \mathrm{hv}, 25-72 \mathrm{hv}$ e $73-168 \mathrm{hv}$, respectivamente):

- amplitude da onda P em DII (36\%, 18\% e $23 \%$ menor em nossa análise);

- amplitude da onda Q em DIII (241\%, $183 \%$ e $176 \%$ maior), aVF (233\%, $130 \%$ e $200 \%$ maior), V5 (10\%, $4 \%$ e $10 \%$ maior) e V6 (13\%, 6\% e 140\% maior em nossos achados);

- amplitude da onda R em V2 (22\%, 33\% e 29\% menor), V5 (41\%, $18 \%$ e $7,5 \%$ maior) e $\mathrm{V} 6(215 \%, 160 \%$ e $128 \%$ maior em nosso estudo);

- amplitude da onda S em V2 (33\%, 36\% e 36\% menor), V4 (25\%, $40 \%$ e $37 \%$ menor) e V6 $(68 \%, 168 \%$ e $48 \%$ maior em nosso estudo);

- duração do complexo QRS em V5 (153\%, maior em $\leq 24 \mathrm{hv}$ e $6,7 \%$ e $26 \%$ menor nos outros grupos em nossos achados);

- $\mathrm{R} / \mathrm{S}$ em V1 $(91 \%, 86 \%$ e $85 \%$ menor), V5 $(73 \%, 85 \%$ e $83 \%$ menor) e V6 (82\%, 90\% e 89\% menor em nossa análise);

- R+S em V2 (29\%, 36\% e 34\% menor em nossa análise);

- S em V1 + R em V6 (87\%, 64\% e 39\% maior em nosso estudo).

Outras diferenças foram achadas entre nossa análise e a de Davignon² em faixas etárias isoladas, como:

- intervalo PR em DII em $\leq 24 h v$ e entre 25-72hv (respectivamente: $11 \%$ e $5,5 \%$ menor); 
- amplitude da onda R em aVR (32\% maior) e V1 (19\% menor) em 25-72hv e em V5 em $\leq 24 \mathrm{hv}$ e em 25-72hv (respectivamente: $41 \%$ e $18 \%$ maior);

- amplitude da onda S em V5 em 25-72hv e 73-168hv (respectivamente: $21 \%$ e $31 \%$ menor);

- ondas $\mathrm{R}+\mathrm{S}$ em V4 em 25-72hv e 73-168hv (respectivamente: $21 \%$ e $24 \%$ menor);

- ondas $\mathrm{S}$ em V2 + R em V5 em 25-72hv e 73-168hv (respectivamente: $67 \%$ e $17 \%$ menor). 


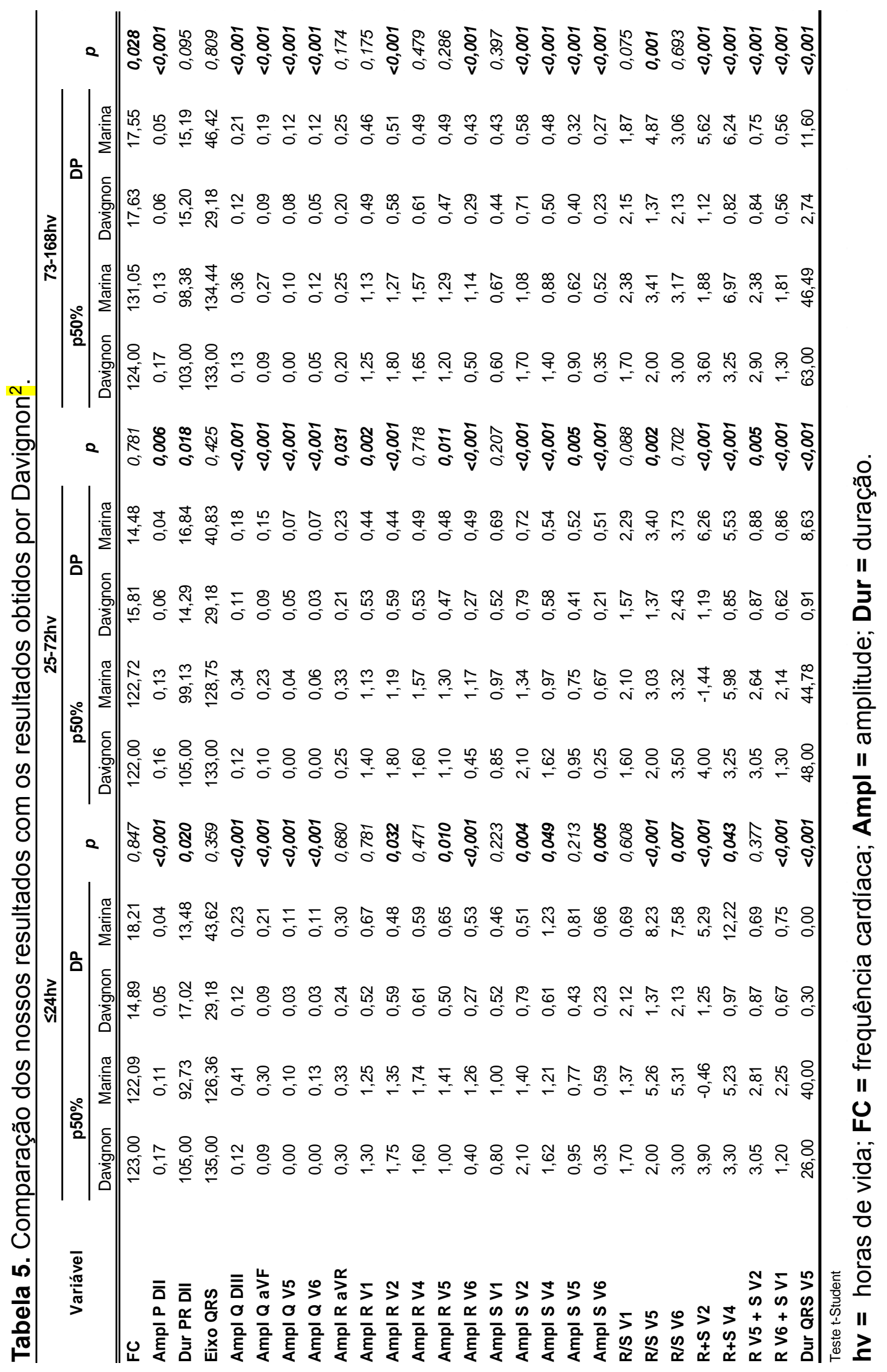


A análise dos $\mathrm{RN}$ segundo a classificação pelo peso de nascimento (tabela 6) mostrou diferenças significantes com relação aos RN GIG. Em relação àqueles classificados como PIG e AIG, os RN GIG mostraram-se mais bradicárdicos (respectivamente, 136,8 $\pm 23,6 \times 125,8 \pm 15,7 \times 114,6 \pm 5,3 \mathrm{bpm}$; $\mathrm{p}=0,021)$.

Tabela 6. Descrição dos parâmetros eletrocardiográficos segundo a classificação dos $\mathrm{RN}$ e resultado dos testes comparativos.

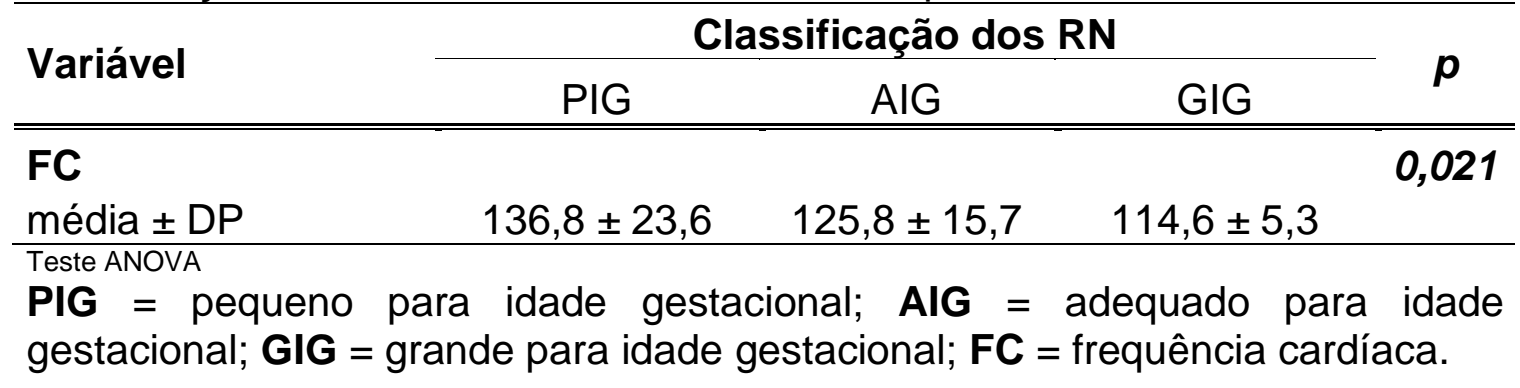


Após a identificação dos resultados estatisticamente significantes pelo teste ANOVA, foi utilizado o teste de Bonferroni para a análise intergrupos (tabela 7). Foi verificada uma menor FC dos RN GIG quando comparados aos RN PIG (diferença entre as médias 22,15 $\pm 7,79 \mathrm{bpm} ; p=0,016$ ) e aos RN AIG (diferença entre as médias $12,17 \pm 4,71 \mathrm{bpm} ; p=0,034$ ).

Tabela 7. Resultado das comparações entre as categorias de classificação dos RN para os parâmetros que apresentaram diferenças.

\begin{tabular}{lcccccc}
\hline \multirow{2}{*}{ Variável } & \multirow{2}{*}{ Comparação } & $\begin{array}{c}\text { Diferença } \\
\text { média }\end{array}$ & $\begin{array}{c}\text { Erro } \\
\text { padrão }\end{array}$ & $\boldsymbol{p}$ & \multicolumn{2}{c}{ IC (95\%) } \\
\cline { 6 - 8 } & & Inferior & Superior \\
\hline \multirow{3}{*}{ FC } & PIG - AIG & 10,95 & 5,65 & 0,167 & $-2,82$ & 24,71 \\
& PIG - GIG & 22,15 & 7,79 & $\mathbf{0 , 0 1 6}$ & 3,16 & 41,14 \\
& AIG - GIG & 11,21 & 5,95 & 0,189 & $-3,31$ & 25,72 \\
& AIG - GIG & 12,17 & 4,71 & $\mathbf{0 , 0 3 4}$ & 0,67 & 23,66 \\
\hline
\end{tabular}

PIG = pequeno para idade gestacional; $\mathbf{A I G}=$ adequado para idade gestacional; GIG = grande para idade gestacional; $\mathbf{F C}$ = frequência cardíaca. 
$\mathrm{Na}$ tabela 8 encontram-se as características maternas.

Tabela 8. Características maternas em $94 \mathrm{RN}$ estudados.

\begin{tabular}{lr}
\hline \multicolumn{1}{c}{ Variável } & \multicolumn{2}{c}{ Descrição $(\mathbf{n}=\mathbf{9 4})$} \\
\hline \hline DM mãe, $\mathbf{n}(\%)$ & \\
Não & $58(61,7)$ \\
DM1 & $10(10,6)$ \\
DM2 & $13(13,8)$ \\
DMG & $13(13,8)$ \\
HA mãe, $\mathbf{n}(\%)$ & \\
Não & $63(67)$ \\
HAC & $16(17)$ \\
DHEG & $1(1,1)$ \\
HAC+DHEG & $14(14,9)$ \\
Idade mãe (anos) & \\
média \pm DP & $29,2 \pm 6,4$ \\
\hline
\end{tabular}

DM = Diabetes mellitus; DM1 = Diabetes mellitus tipo 1; DM2 $=$ Diabetes mellitus tipo 2; DMG = Diabetes mellitus gestacional; $\mathbf{H A}=$ hipertensão arterial; HAC = hipertensão arterial crônica; DHEG = doença hipertensiva específica da gravidez. 
Ao analisar a influência do DM na população estudada, observou-se que a presença de DM2, quando comparada às mães sem DM, com DM1 e DMG, resultou em diferença estatisticamente significante, respectivamente, em:

- aumento da FC $(140,9 \pm 18,0 \times 124,8 \pm 15,4 \times 118,7 \pm 8,6 \times$ $121,4 \pm 17,4 \mathrm{bpm} ; p=0,002)$

- aumento da amplitude da onda P em DII $(0,17 \pm 0,03 \times 0,12 \pm 0,04 \times$ $0,12 \pm 0,05 \times 0,13 \pm 0,04 \mathrm{mV} ; p=0,006)$;

- redução da duração do intervalo QT em V2 $(255,4 \pm 47,7$ x $289,0 \pm 47,1 \times 284,0 \pm 45 \times 310,8 \pm 51,4 \mathrm{~ms} ; p=0,033) ;$

- maior proporção de ondas $\mathrm{T}$ plus minus e minus plus na derivação DIII (7,7\% e 15,4\%; 0\% e 1,7\%; 0\% e 0\%; 0\% e 0\%; $p=0,011$.

Já a presença da DMG evidenciou um aumento significativo do intervalo QTc em relação às mães com DM1 $(436,9 \pm 47,1 \times 363,8 \pm 119,3 \mathrm{~ms} ; p=0,032)$. Nos anexos Ah e Ai encontram-se os resultados referentes à influência do DM na população estudada.

A presença da HA materna não mostrou influência nos parâmetros eletrocardiográficos avaliados. 


\section{DISCUSSÃO}

Este é o primeiro trabalho na população brasileira a analisar o padrão eletrocardiográfico em uma coorte de RN. Ao analisar a literatura mundial, encontram-se apenas estudos antigos e sem correlação dos achados eletrocardiográficos com possíveis alterações estruturais cardíacas. Em 1971, Hastreiter et Abella ${ }^{1}$ publicaram um estudo de revisão visando descrever o ECG normal em RN, dividindo-os em três grupos: 0-24 hora, 1-7 dias e 7-30 dias de vida. Nesta revisão, foram apontados possíveis vieses como a diferença de aparelhos e posicionamento de eletrodos entre os estudos revisados, a não divisão por horas de vida em todos os estudos e a falta de informações clínicas sobre a gestação e evolução do neonato. Rijnbeek et al ${ }^{5}$ realizaram na Holanda, no ano de 2001, um estudo semelhante, incluindo 1.912 pacientes. Entretanto, apenas 44 eram neonatos, número insuficiente para conclusões definitivas. Nenhum desses autores avaliou os parâmetros do ECG em RN com correlação de imagem ecocardiográfica que comprovasse um coração anatomicamente normal. Além disso, nenhum desses estudos apresentou informações sobre o pré-natal, comorbidades maternas e fatores de risco para cardiopatia congênita nos RN estudados.

Na população brasileira, Palhares et al $^{6}$ analisaram o ECG de 486.014 indivíduos hígidos com idade superior a um ano em um serviço de atenção primária. Foram analisados parâmetros tais como FC, eixo do QRS e da onda T, duração da onda P e do complexo QRS e QTc por diferentes métodos. Os resultados foram demonstrados em curvas de percentis, à semelhança de Davignon et $\mathrm{al}^{2}$. Na literatura consultada, até outubro de 2020, não foram 
encontradas publicações sobre o ECG no período neonatal na população brasileira.

Publicado em 1979, o estudo de Davignon et al² é, até hoje, o trabalho mais completo realizado sobre o tema, sendo analisada uma coorte de 2.141 crianças canadenses, dentre as quais $668 \mathrm{RN}$, sendo 549 nos primeiros 7 dias de vida. Este trabalho tem sido utilizado até o momento como referência para avaliar RN. Ao compararmos os valores encontrados com os valores estimados extraídos do estudo de Davignon ${ }^{2}$, notamos diferenças estatisticamente significantes em diversos parâmetros em todas as faixas etárias, como:

- $\quad$ menor amplitude da onda P em DII;

- maior amplitude da onda Q em DIII, aVF e V5;

- menor amplitude da onda R em V2, maior em V5 e V6;

- menor amplitude da onda S em V2 e V4, e maior em V6;

- maior duração do complexo QRS em V5 em $\leq 24 \mathrm{hv}$ e menor duração em outros grupos etários;

- $\quad$ menor R/S em V1, V5 e V6;

- menor R+S em V2;

- maior S em V1 + R em V6.

Outras diferenças foram achadas entre nossa análise e a de Davignon² em faixas etárias isoladas, como:

- menor intervalo PR em DIl em $\leq 24 \mathrm{hv}$ e entre 25-72hv;

- maior amplitude da onda R em aVR e menor em V1 em 25-72hv;

- maior amplitude da onda R em V5 em $\leq 24 \mathrm{hv}$ e em 25-72hv;

- menor amplitude da onda S em V5 em 25-72hv e 73-168hv; 
- menores ondas R + S em V4 em 25-72hv e 73-168hv;

- menores ondas S em V2 + R em V5 em 25-72hv e 73-168hv.

Essas diferenças mostram que os parâmetros de normalidade eletrocardiográficos apresentados por Davignon ${ }^{2}$ podem não ser ideais na interpretação do ECG em RN brasileiros na atualidade. Além da possível diferença antropométrica populacional (Canadá x Brasil), pode-se também citar como justificativa para corroborar as diferenças encontradas que no estudo de Davignon $^{2}$ não houve triagem cardiológica, exame de imagem ou seguimento dos RN. Deste modo, não há comprovação de que esses neonatos, de fato, não apresentavam cardiopatia estrutural.

Ao comparar os valores encontrados aos das Diretrizes da Sociedade Brasileira de Cardiologia ${ }^{4}$, observou-se que houve diferença significativa na maioria dos parâmetros analisados. Todos os parâmetros apresentaram diferença estatística, com exceção das relações R/S em V1 e R/S em V6 no grupo $\leq 24 \mathrm{hv}$ e na amplitude da onda R em V6 no grupo $25-72 \mathrm{hv}$. No grupo $73-$ $168 \mathrm{hv}$, nenhum parâmetro foi semelhante. Sabe-se que estas Diretrizes foram elaboradas baseando-se na literatura internacional, em especial no estudo de Davignon ${ }^{2}$, até hoje o maior e mais completo sobre o assunto. Assim, assumiuse que as populações estudadas em outros países seriam comparáveis à população brasileira.

A discrepância do estudo de Davignon ${ }^{2}$ com os resultados observados por nós demonstra a necessidade de pesquisas adicionais em centros brasileiros para comprovação de nossos achados e revisão das Diretrizes brasileiras atuais. 
Ao analisar as características clínicas dos $\mathrm{RN}$ estudados, pode-se notar um menor número de $\mathrm{RN}$ no grupo $\leq 24 \mathrm{hv}$. Este fato era esperado, já que $\mathrm{RN}$ em idade tão precoce muitas vezes ainda não têm indicação de realização de ECO e, portanto, o ECG também não foi realizado. A presença de achados como sopro cardíaco fisiológico, canal arterial amplo e aumento da pressão pulmonar, que podem ocorrer nas primeiras horas de vida, dificulta a análise de cardiopatias pelo ECO. Por esta razão, o exame é realizado preferencialmente após o primeiro dia de vida.

Ao separar os $\mathrm{RN}$ em três grupos etários ( $\leq 24 \mathrm{hv}$, entre $25-72 \mathrm{hv}$ e entre 73-168hv), verificaram-se diferenças significantes em parâmetros eletrocardiográficos importantes, tais como orientação espacial das ondas $T$ nas derivações V1, V2, V3 e V4. A maior proporção de ondas T positivas nos grupos etários mais jovens pode ser explicada pela maior pressão da artéria pulmonar encontrada nessa fase precoce, levando a uma repolarização iniciada no ventrículo direito. Com a queda fisiológica da pressão da artéria

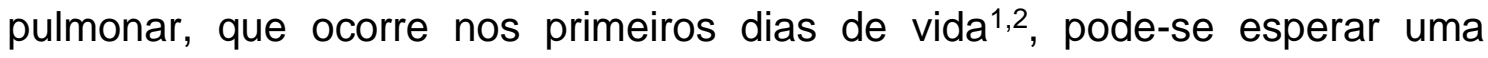
alteração da repolarização ventricular para o padrão infantil, levando a uma menor proporção de ondas T positivas nas derivações precordiais (V1 a V4). Não houve diferença estatística nos demais parâmetros eletrocardiográficos estudados.

A proporção de RN PIG, AIG e GIG, além da proporção de $\mathrm{RN}$ do gênero feminino e masculino foi conforme a esperada na literatura em geral. A taxa de partos cesariana entre os $\mathrm{RN}$ estudados $(57,4 \%)$ foi consideravelmente acima da recomendada pela Organização Mundial de Saúde (10 a 15\% $\left.{ }^{19}\right)$. Este fato pode ser justificado pelas características de alto risco da população 
atendida no HC-FMUSP, hospital terciário de referência na América Latina. Ainda assim, a taxa encontrada é semelhante à taxa de cesarianas no Brasil $(59 \%)^{10}$

Também foi possível notar uma diferença na análise do ECG dos RN GIG, os quais apresentaram menor FC em relação aos RN PIG. Os RN PIG provavelmente são submetidos a um maior estresse intra-útero ${ }^{20,21}$, e podem apresentar níveis plasmáticos de cortisol e aldosterona elevados, especialmente após $24 \mathrm{~h}$ de vida. O aumento da produção de hormônios de estresse poderia justificar a diferença na FC basal observada em nosso estudo. Também foi observada nos RN GIG menor amplitude do complexo QRS nas derivações V3 e V5 e maior amplitude do QRS na derivação V6 em relação aos RN AIG. Essa diferença poderia ser explicada pela provável maior massa miocárdica 22 , especialmente do ventrículo esquerdo, dos RN GIG.

Foi realizada a análise de RN filhos de mães com DM e HA por essas serem as duas doenças maternas mais comuns no pré-natal e com grande morbidade para os $\mathrm{RN}$ durante o período perinatal. Verificou-se que os filhos de mães com DM2 apresentaram maior FC, maior amplitude da onda $\mathrm{P}$ na derivação DII, aumento da amplitude do complexo QRS na derivação DIII e maior proporção de ondas T plus minus e minus plus na derivação DIII em relação aos $\mathrm{RN}$ filhos de mãe sem DM. É sabido que $\mathrm{RN}$ filhos de mães com DM apresentam hipertrofia miocárdica, especialmente hipertrofia septal7 ${ }^{7,8}$. É provável que mães com DM2, por apresentarem DM prévio à gestação e muitas vezes comorbidades como obesidade e síndrome metabólica, apresentem $\mathrm{RN}$ mais afetados em relação àquelas com DMG (com início geralmente na segunda metade da gestação) e com DM1 (geralmente 
patologia isolada e com melhor controle antes da gestação). A presença de HA materna não parece influenciar na análise do ECG em RN. 


\section{CONCLUSÕES}

A análise dos padrões eletrocardiográficos de $94 \mathrm{RN}$ a termo, sem alterações morfológicas e funcionais cardíacas nos permitiu chegar às seguintes conclusões:

1. A maior proporção de ondas $T$ positivas nos grupos etários mais jovens nas derivações $\mathrm{V} 1, \mathrm{~V} 2, \mathrm{~V} 3$ e V4 indica que a idade do recém-nascido deve ser considerada na avaliação do ECG durante a primeira semana de vida.

2. Houve diferenças significantes na maioria dos parâmetros eletrocardiográficos analisados ao comparar os valores encontrados aos das Diretrizes da Sociedade Brasileira de Cardiologia 4 .

3. Houve diferença significante entre os valores observados neste estudo com aqueles observados por Davignon ${ }^{2}$, evidenciando que os parâmetros de normalidade eletrocardiográficos apresentados por Davignon ${ }^{2}$ podem não ser ideais na interpretação do ECG em RN brasileiros na atualidade.

4. Com relação à influência da classificação do peso em relação à idade gestacional no padrão eletrocardiográfico, observou-se que a FC foi maior nos RN PIG em relação aos RN GIG.

5. Os filhos de mães com DM2 apresentaram diferenças significantes, como aumento da FC, maior amplitude da onda $\mathrm{P}$ e diferenças na repolarização ventricular em relação aos $\mathrm{RN}$ filhos de mãe sem DM. 
6. A presença de HA materna não influenciou o padrão eletrocardiográfico dos RN. 


\section{LIMITAÇÕES}

Há dificuldades importantes na realização de ECG em neonatos, como caixa torácica pequena e grande mobilidade dos RN. Assim, foi optado pela realização de todos os ECG pelo mesmo pesquisador, visando evitar a influência de posicionamento dos eletrodos nos resultados obtidos. Isso levou a um número limitado de RN (94) estudados, o que pode ter influenciado nos resultados obtidos. É provável que com grupos maiores, outras diferenças estatísticas possam ser encontradas.

A análise referente à classificação dos $\mathrm{RN}$ segundo peso em relação à IG foi prejudicada pelo reduzido número de PIG (9) e GIG (8) estudados, o que pode refletir em resultados diferentes dos encontrados em análises com populações maiores. Da mesma forma, a análise do grupo $\leq 24 \mathrm{hv}$ também pode ter sido prejudicada pelo reduzido número de RN neste grupo (11).

Não foi possível a utilização de testes estatísticos para comparação dos nossos achados aos de Davignon ${ }^{2}$ devido ao não conhecimento das médias e desvios-padrão encontrados por este autor. Assim, a comparação se deu de forma empírica, através de estimativa dos valores extraídos dos gráficos de percentis publicados por este autor. 


\section{ANEXOS}

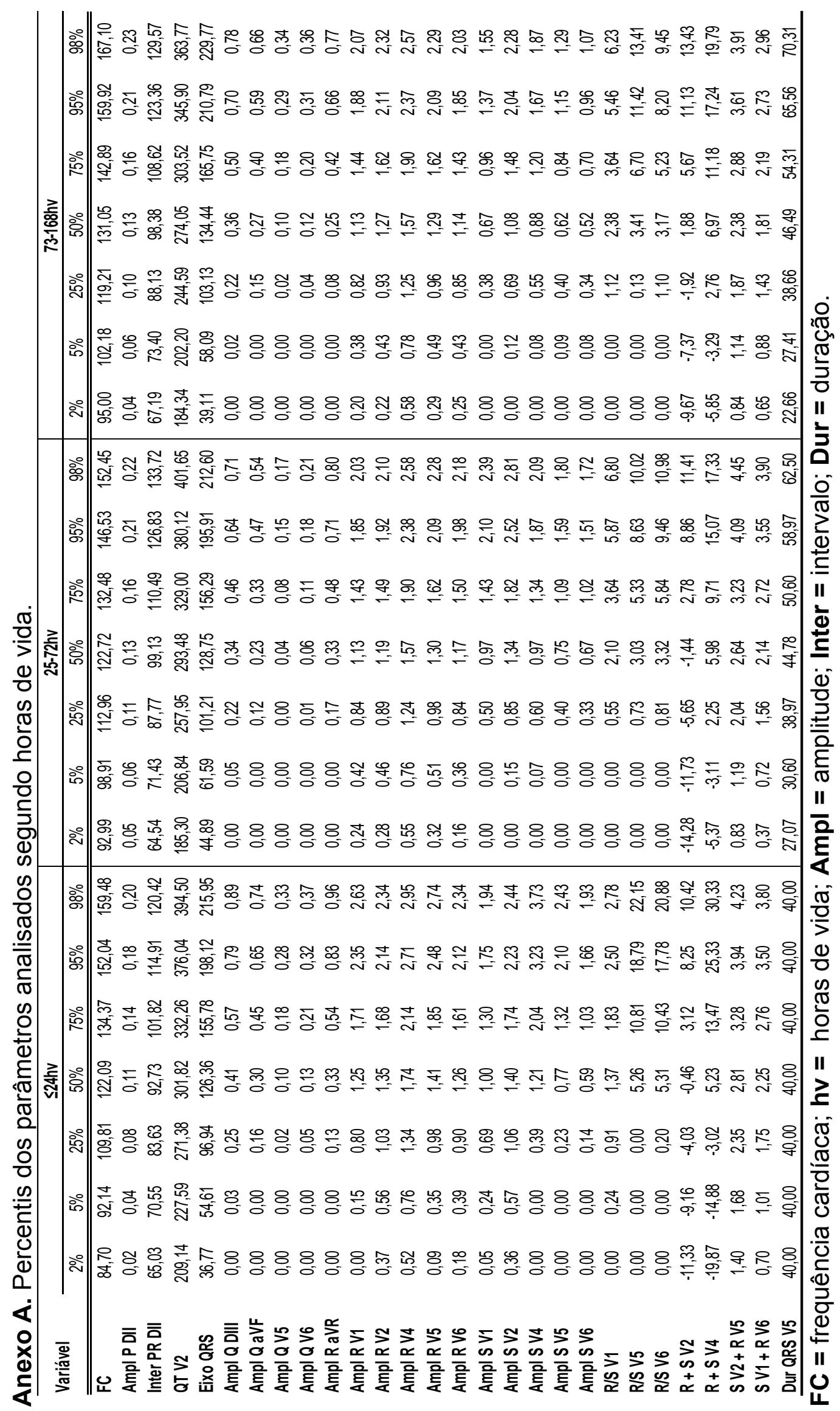


Anexo B. Percentis da FC versus horas de vida.

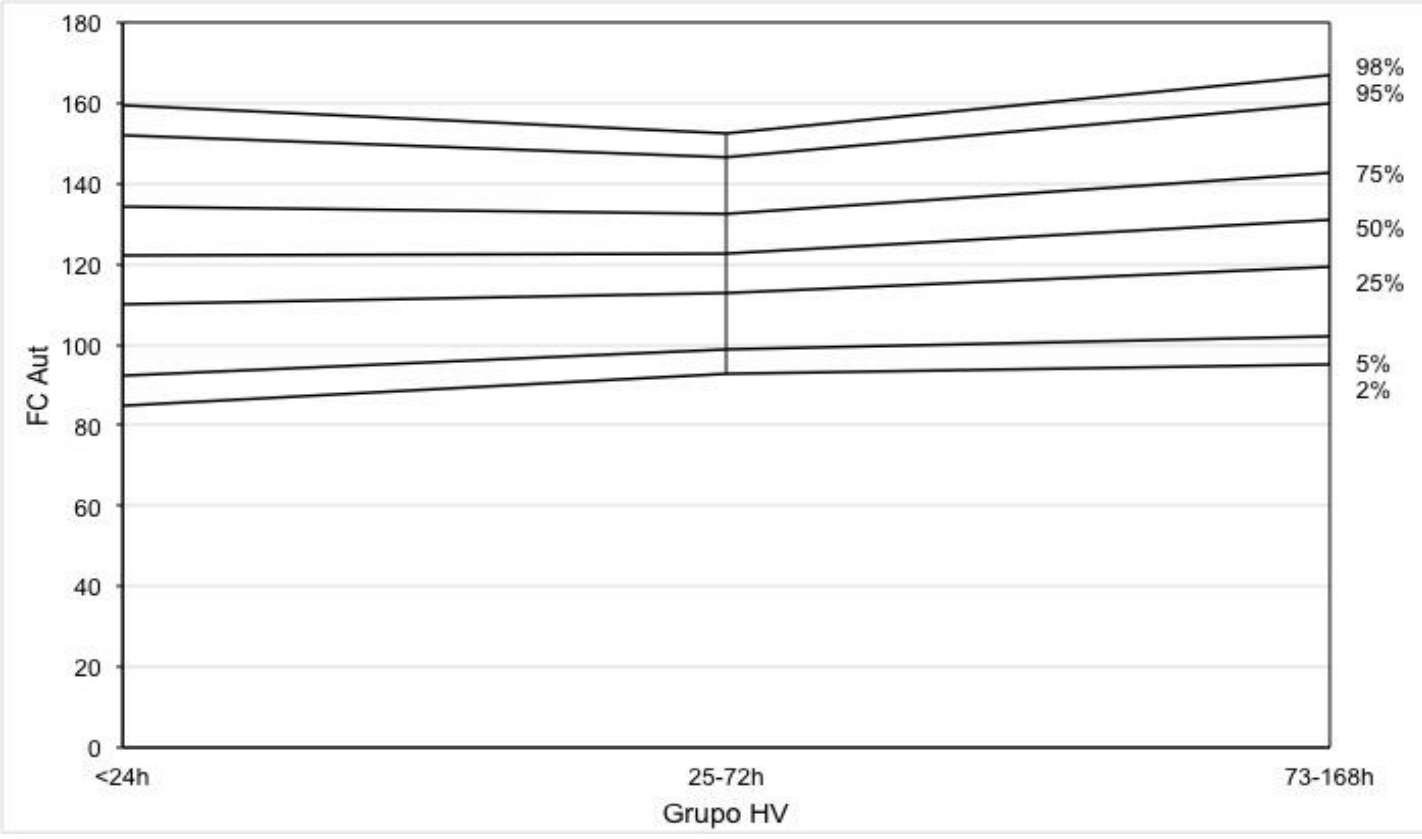

Anexo C. Percentis da FC versus intervalo PR na derivação DII segundo horas de vida.

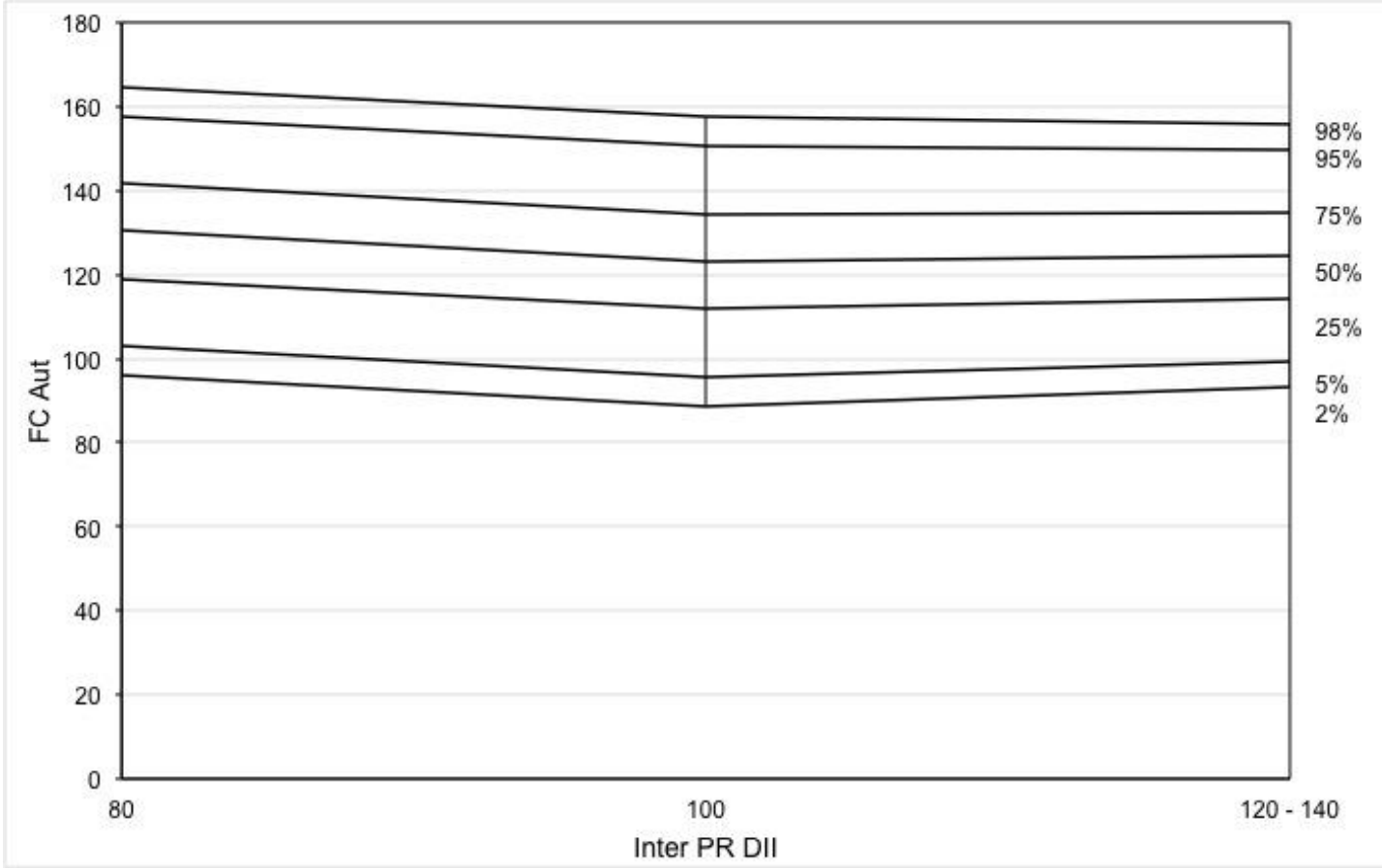


Anexo D. Percentis da amplitude da onda P na derivação DIl versus horas de vida.

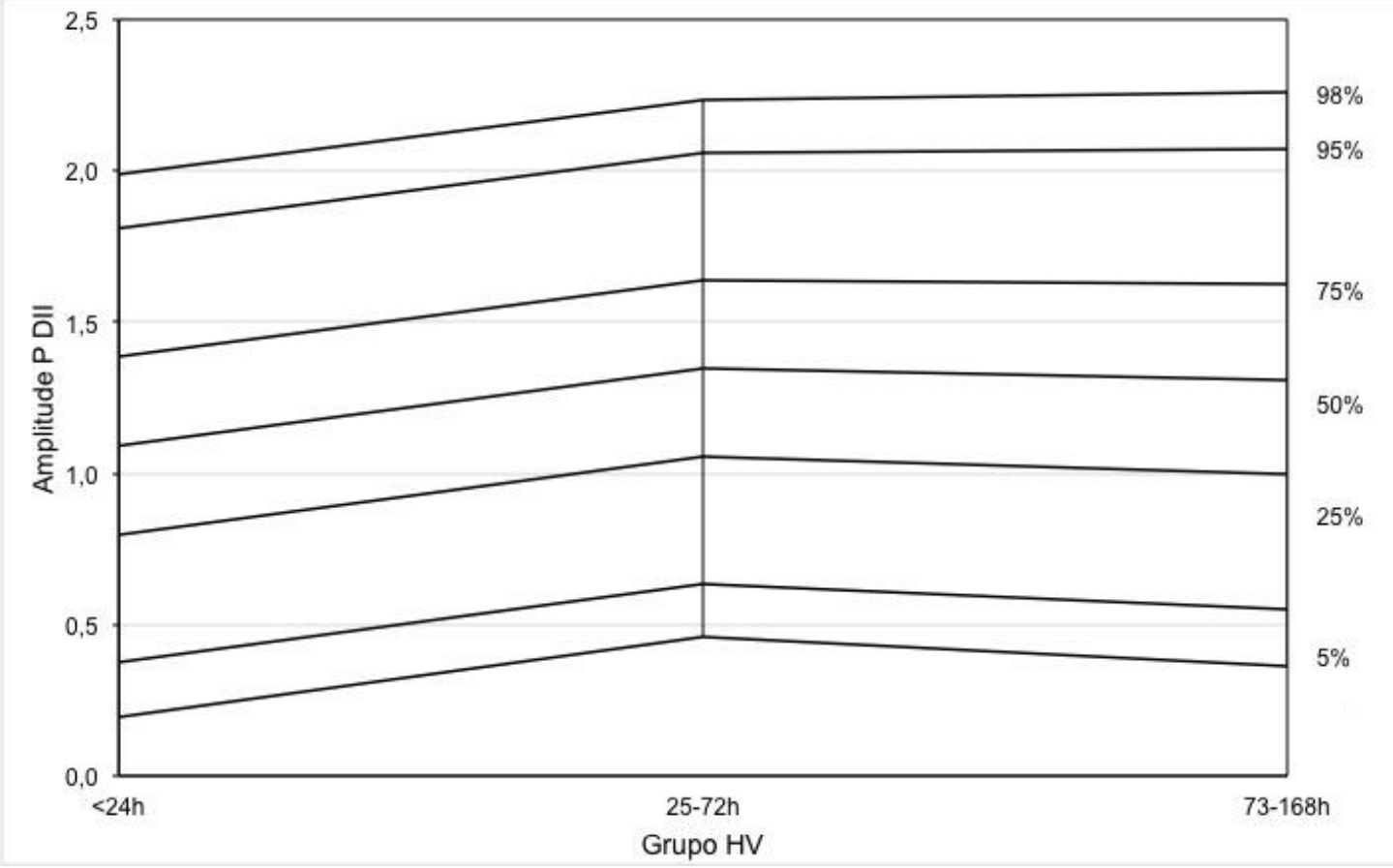

Anexo E. Percentis do intervalo PR na derivação DIl versus horas de vida.

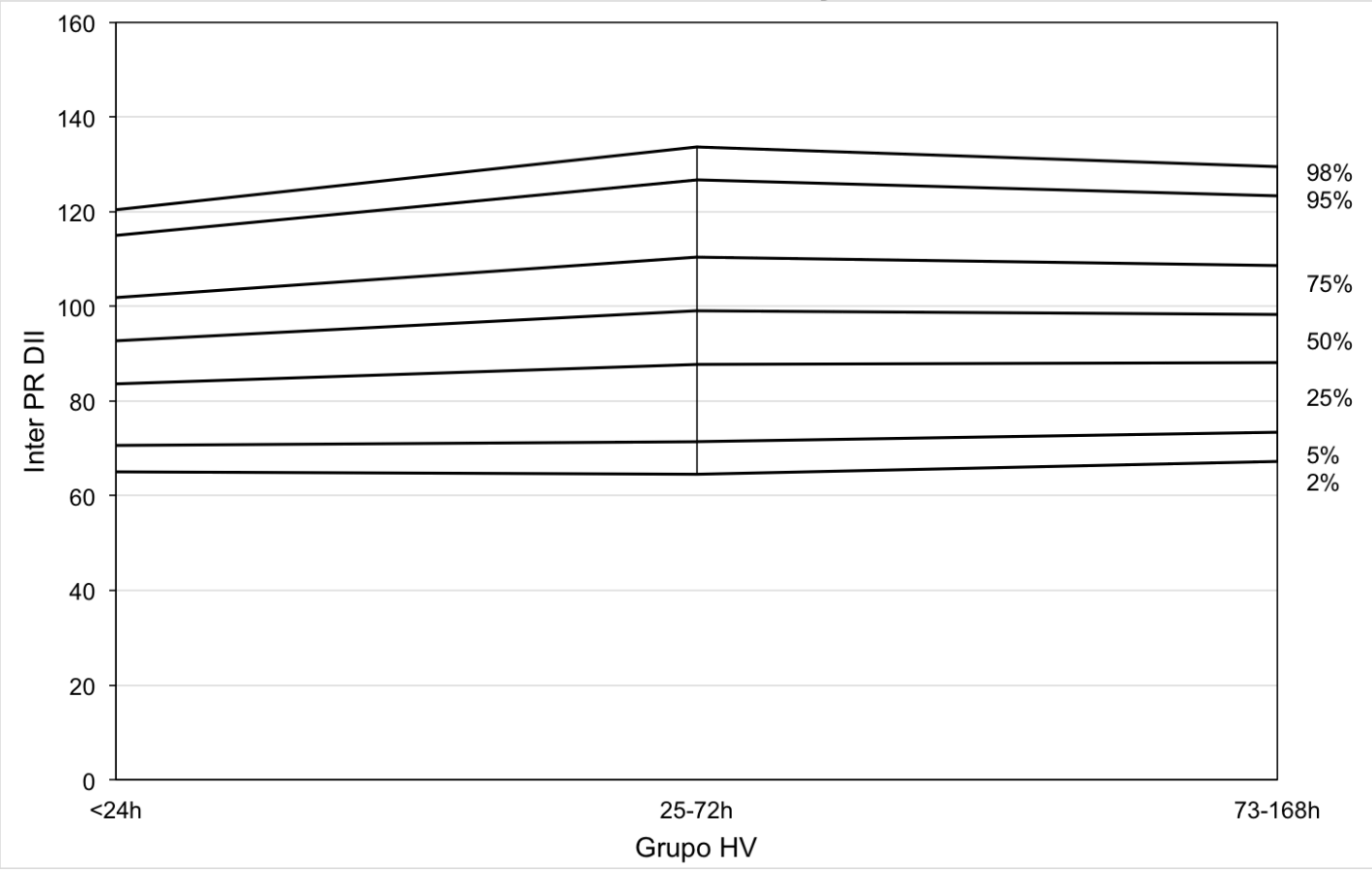


Anexo F. Percentis do intervalo QT na derivação V2 versus horas de vida.

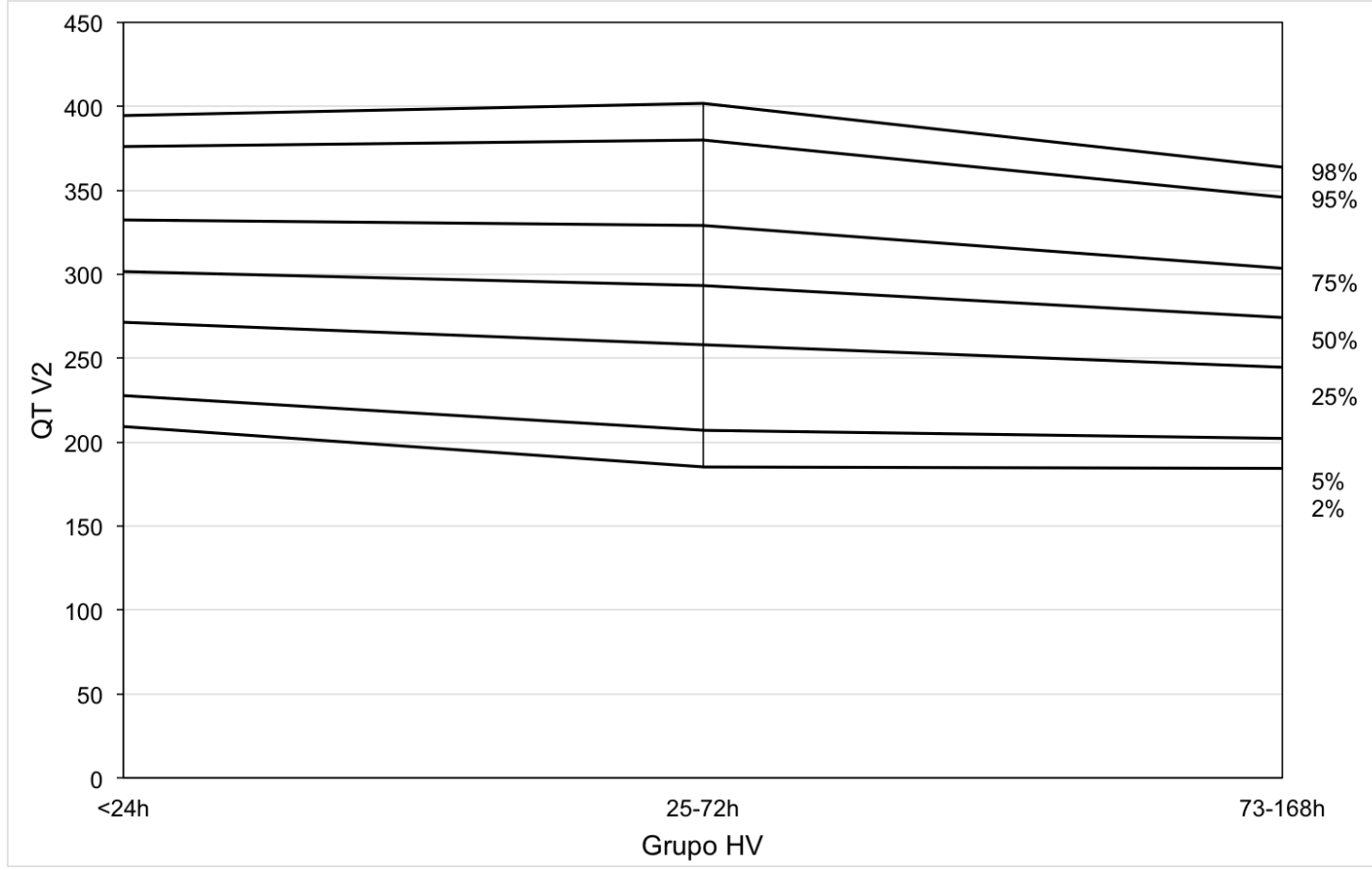

Anexo G. Percentis do eixo QRS versus horas de vida.

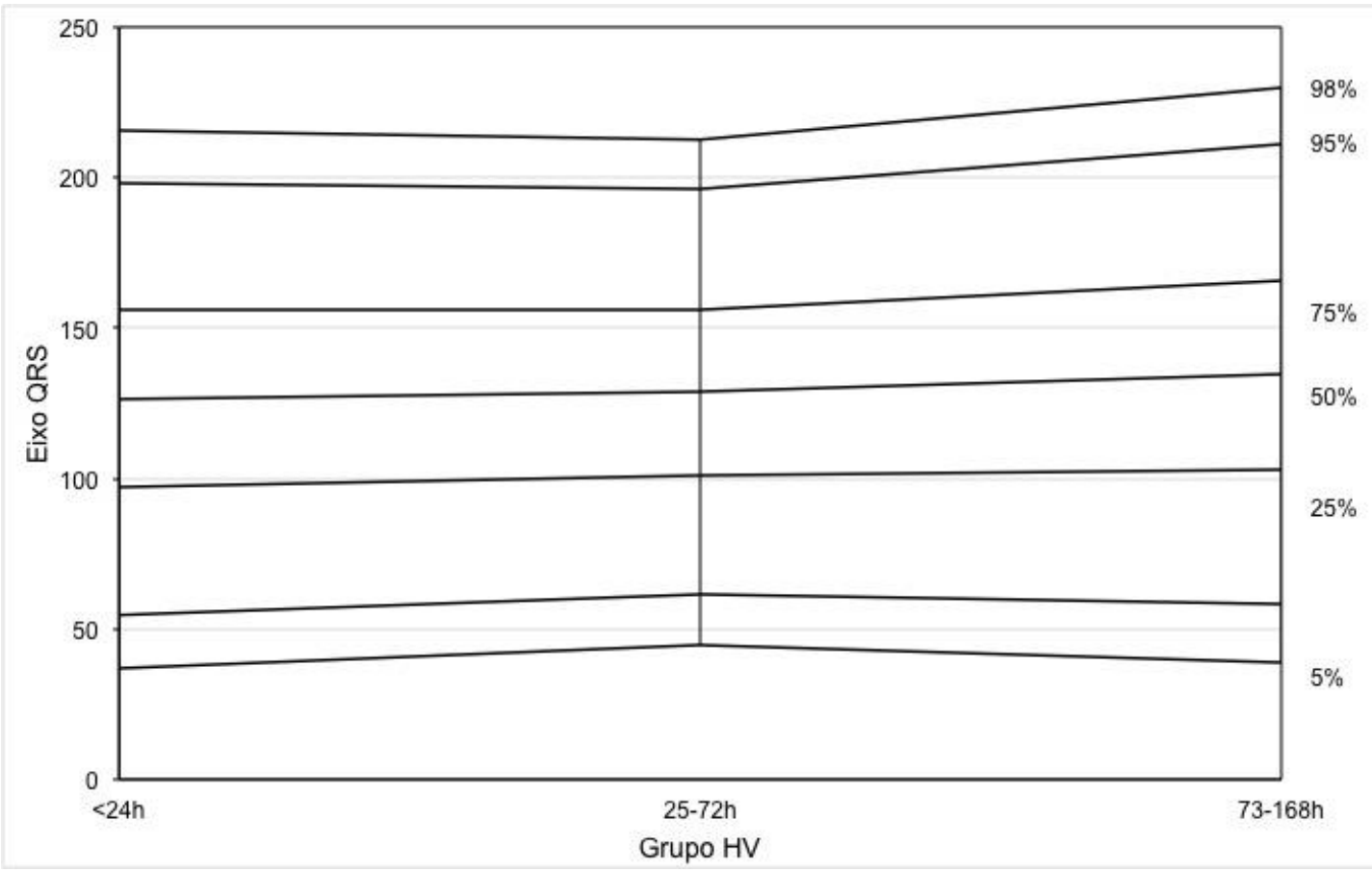


Anexo H. Percentis da amplitude da onda $Q$ na derivação DIII versus horas de vida.

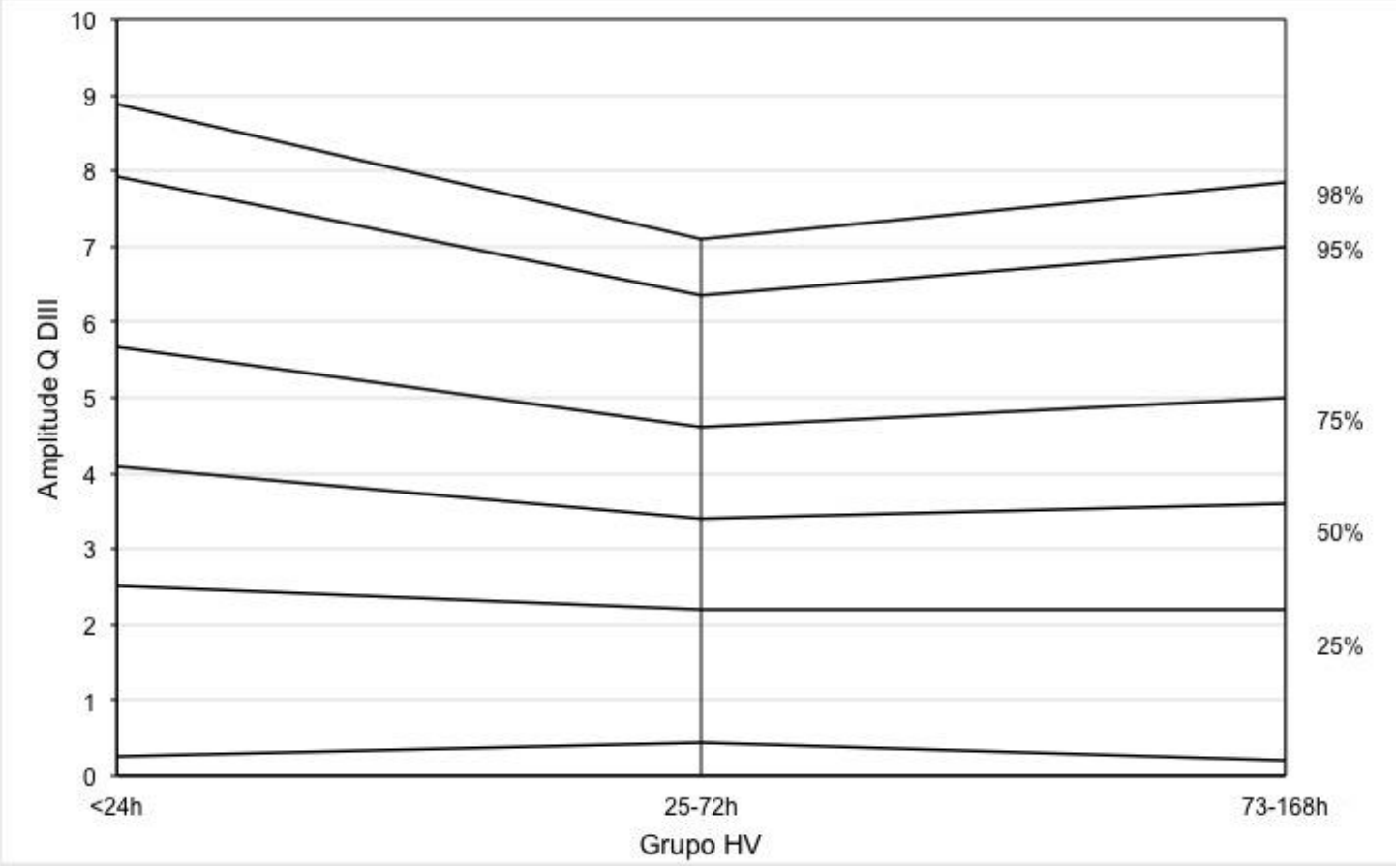

Anexo I. Percentis da amplitude da onda $Q$ na derivação aVF versus horas de vida.

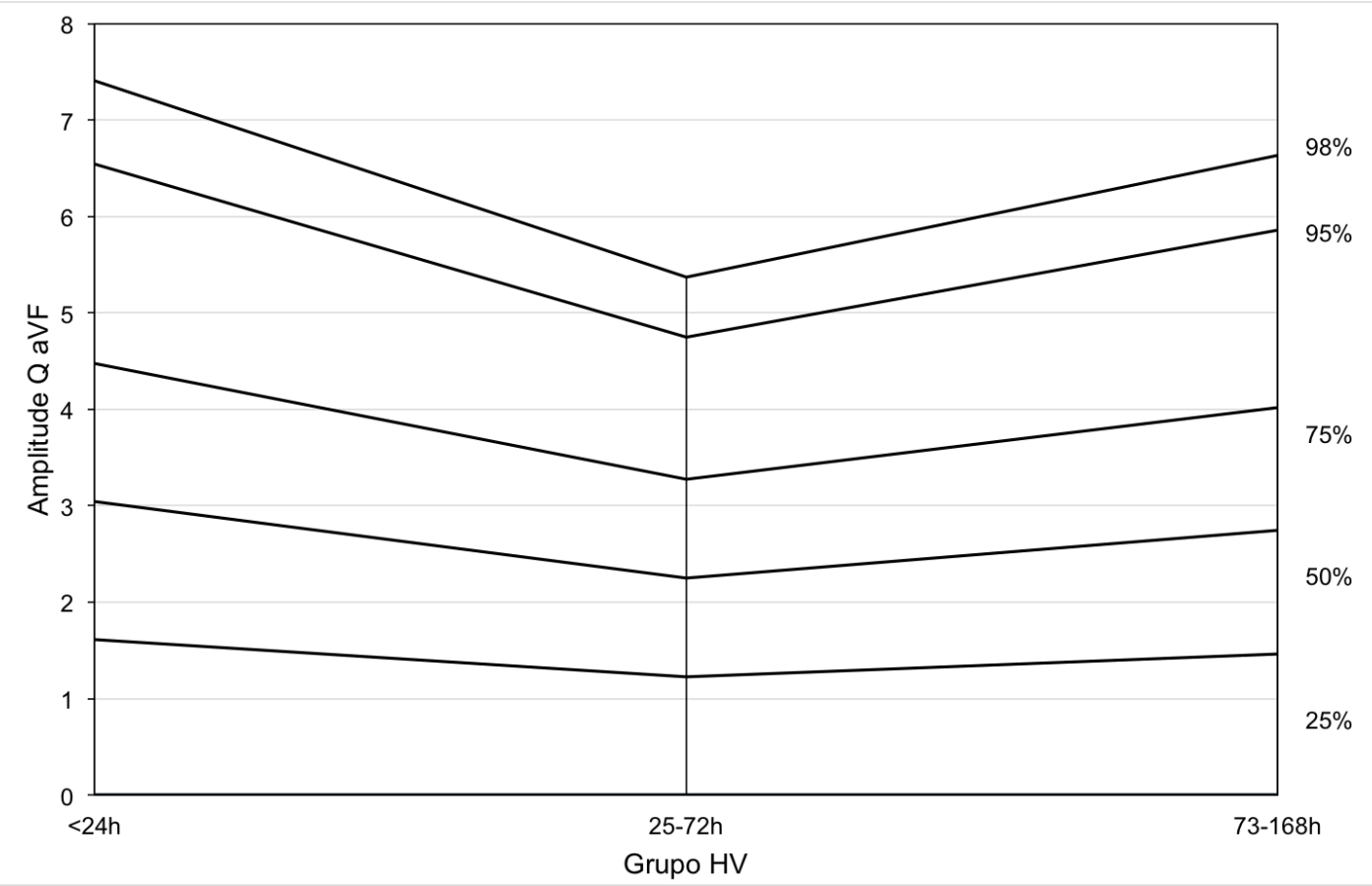


Anexo J. Percentis da amplitude da onda Q na derivação V5 versus horas de vida.

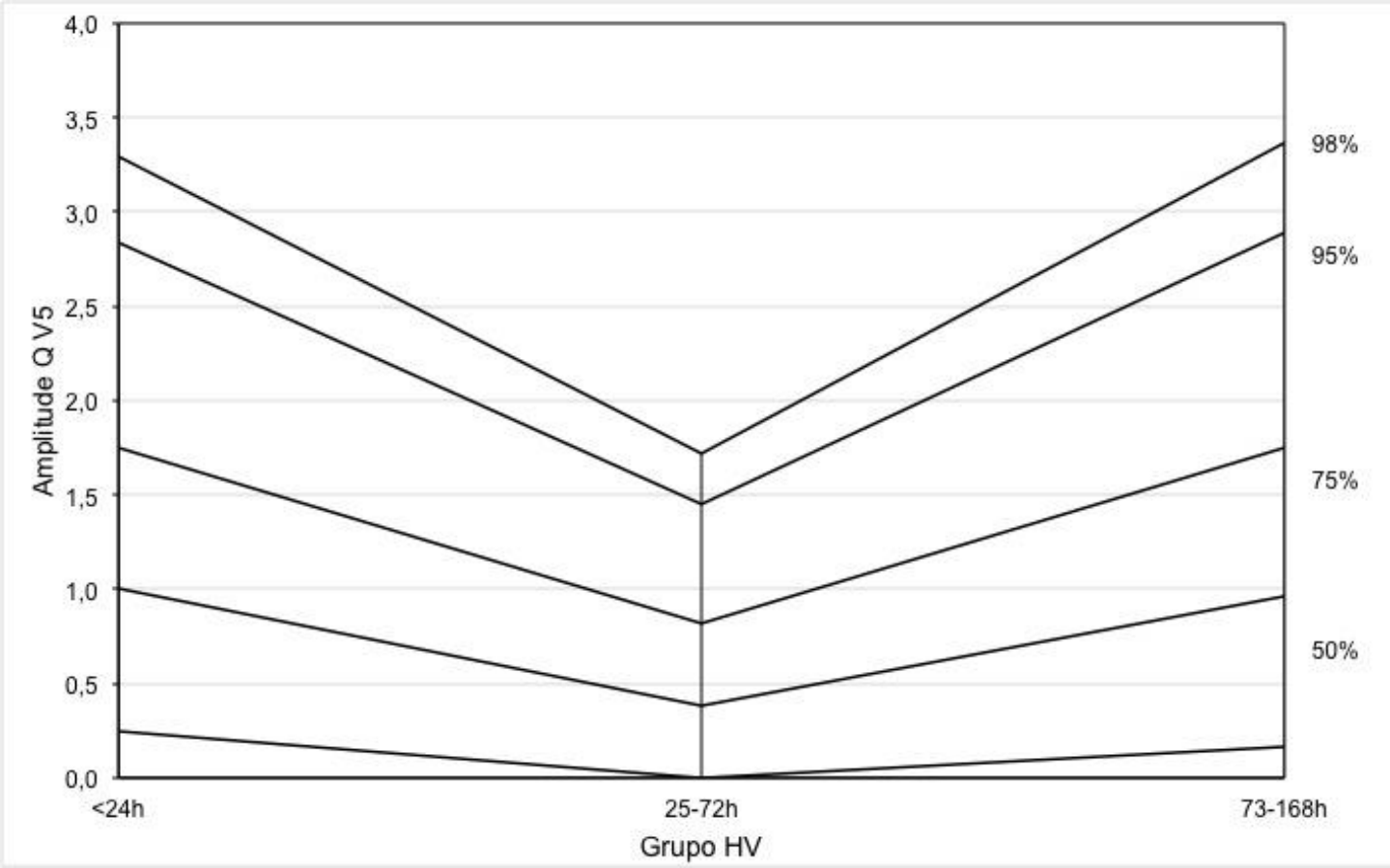

Anexo L. Percentis da amplitude da onda $Q$ na derivação V6 versus horas de vida.

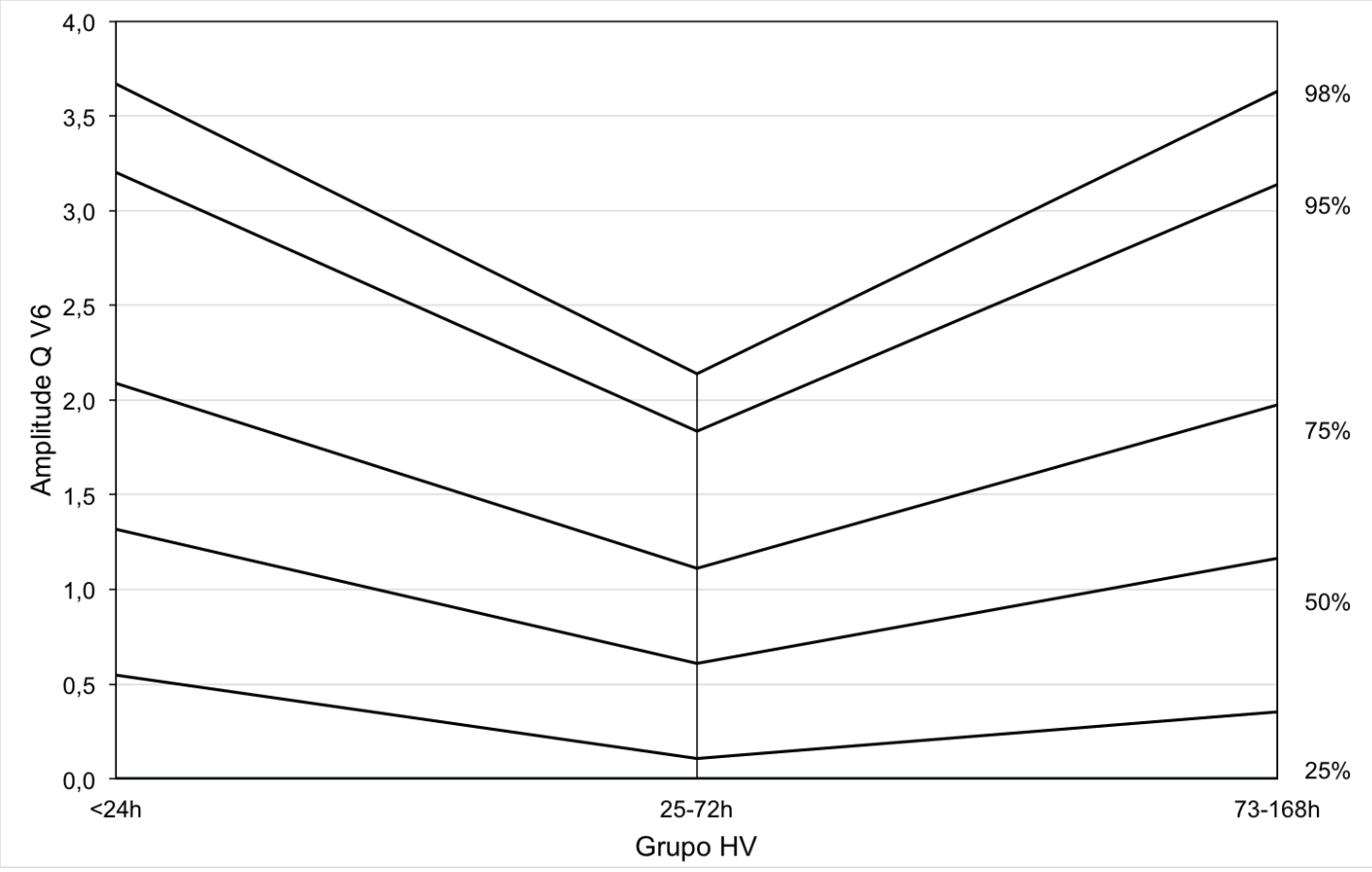


Anexo M. Percentis da amplitude da onda $R$ na derivação aVR versus horas de vida.

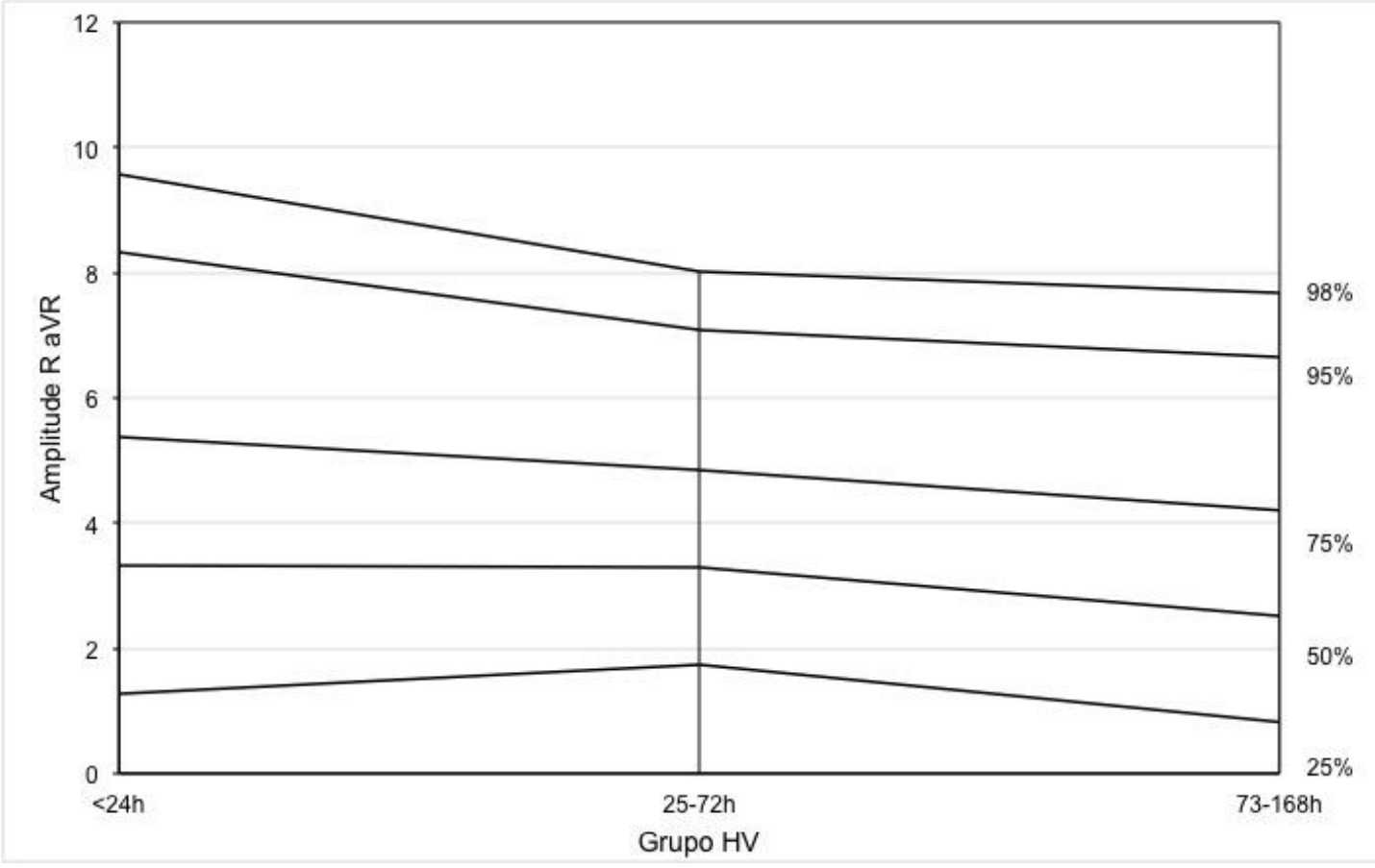

Anexo N. Percentis da amplitude da onda R na derivação V1 versus horas de vida.

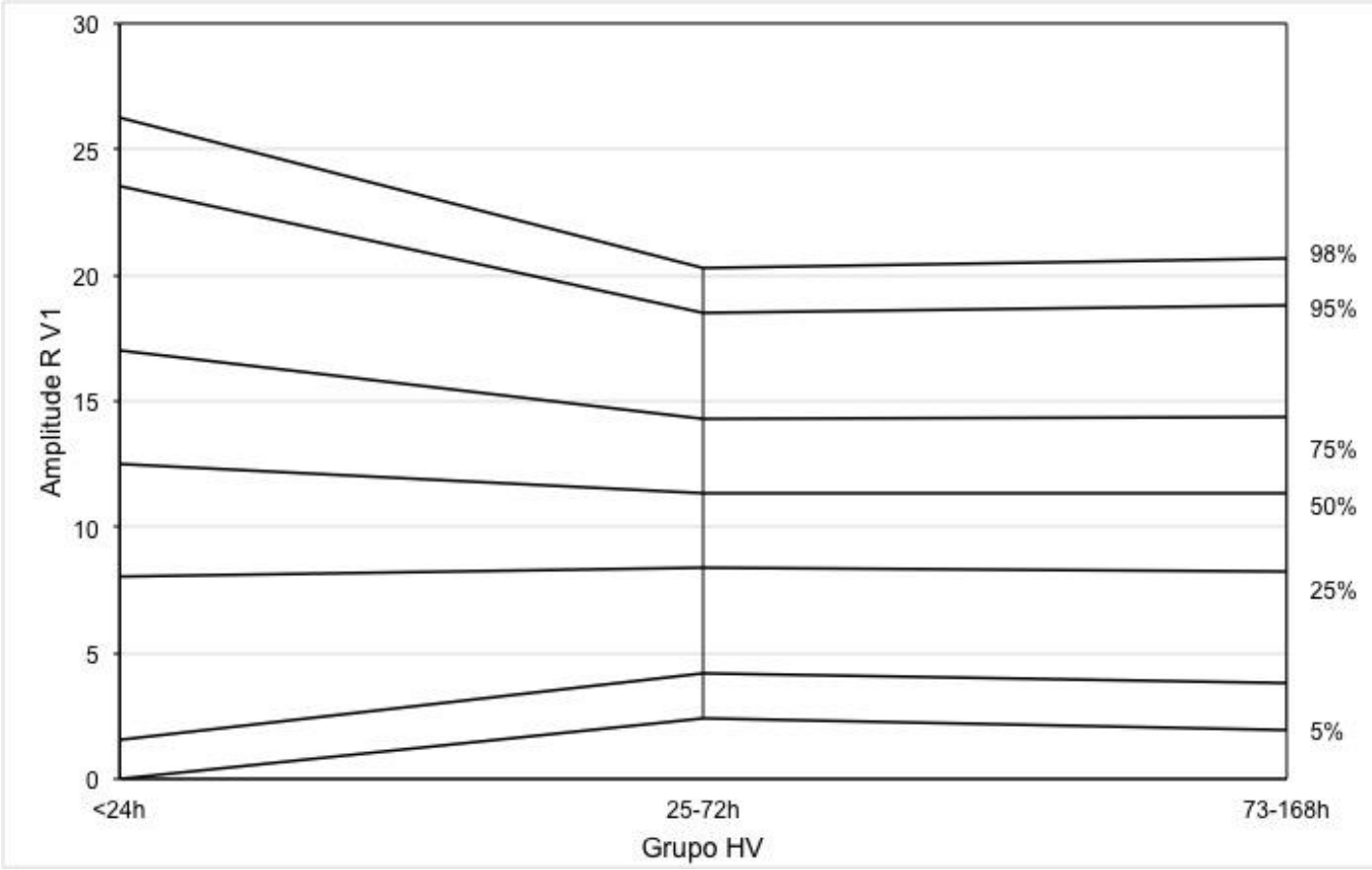


Anexo O. Percentis da amplitude da onda $\mathrm{R}$ na derivação V2 versus horas de vida.

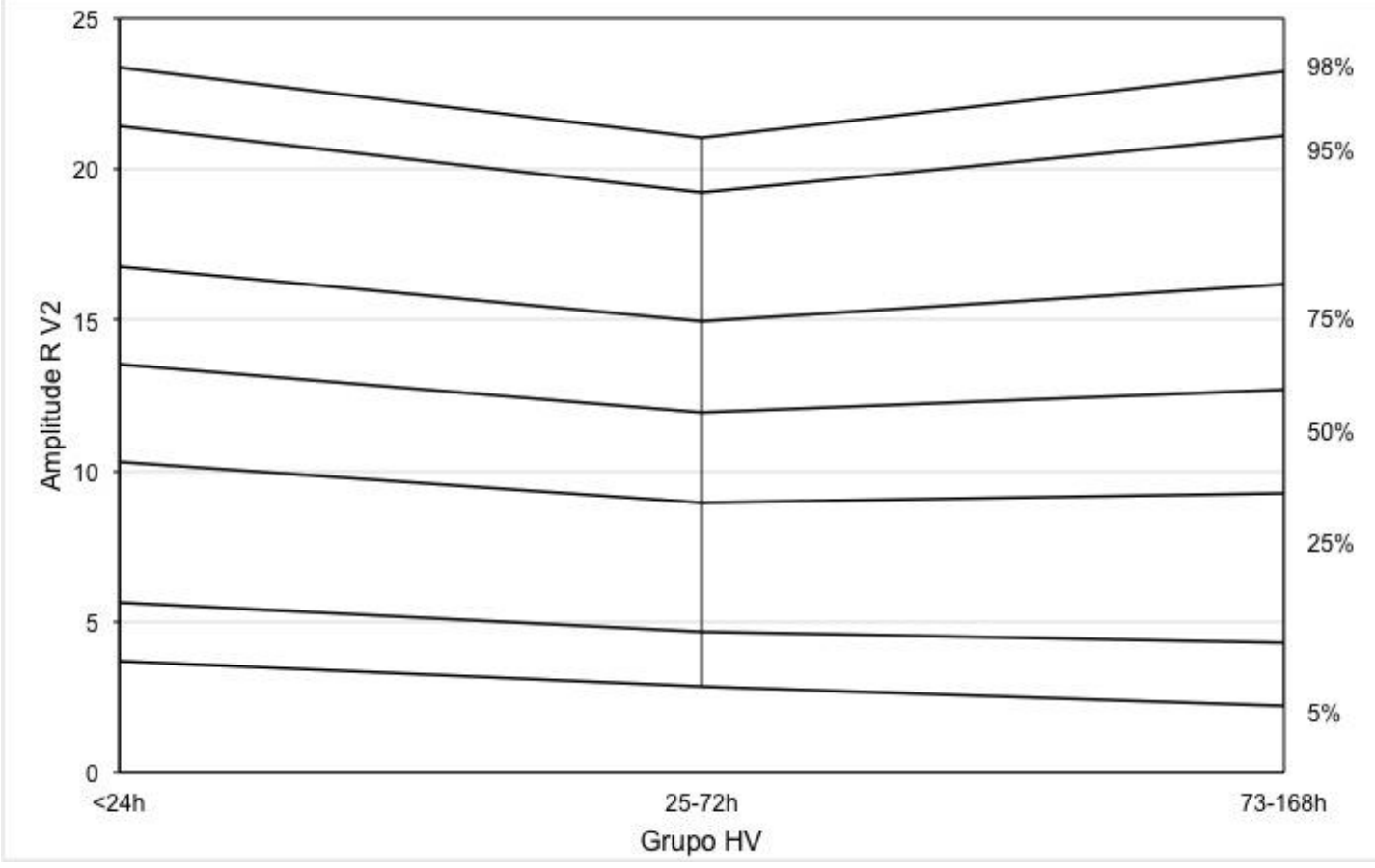

Anexo P. Percentis da amplitude da onda $R$ na derivação V4 versus horas de vida.

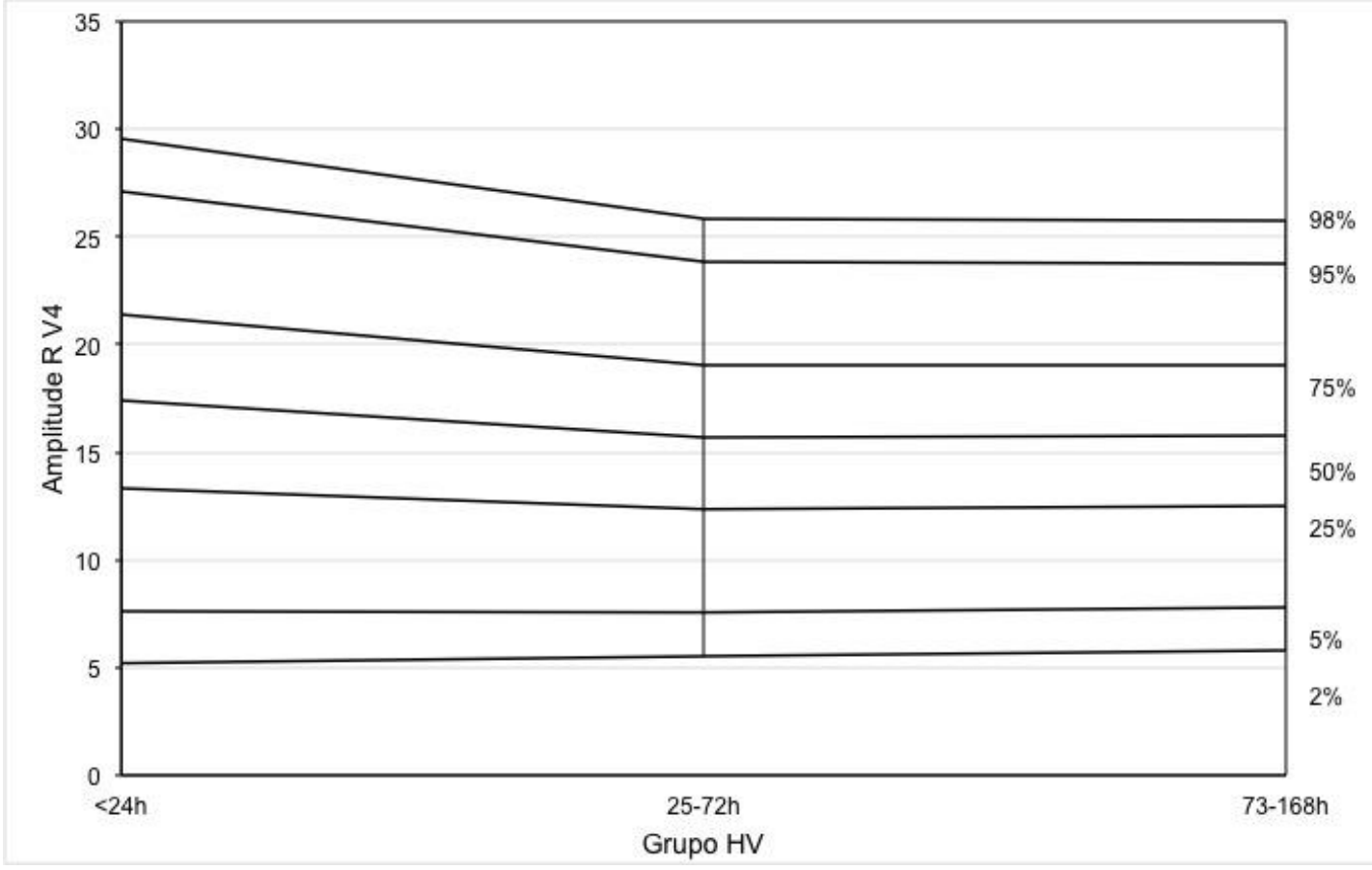


Anexo Q. Percentis da amplitude da onda $\mathrm{R}$ na derivação V5 versus horas de vida.

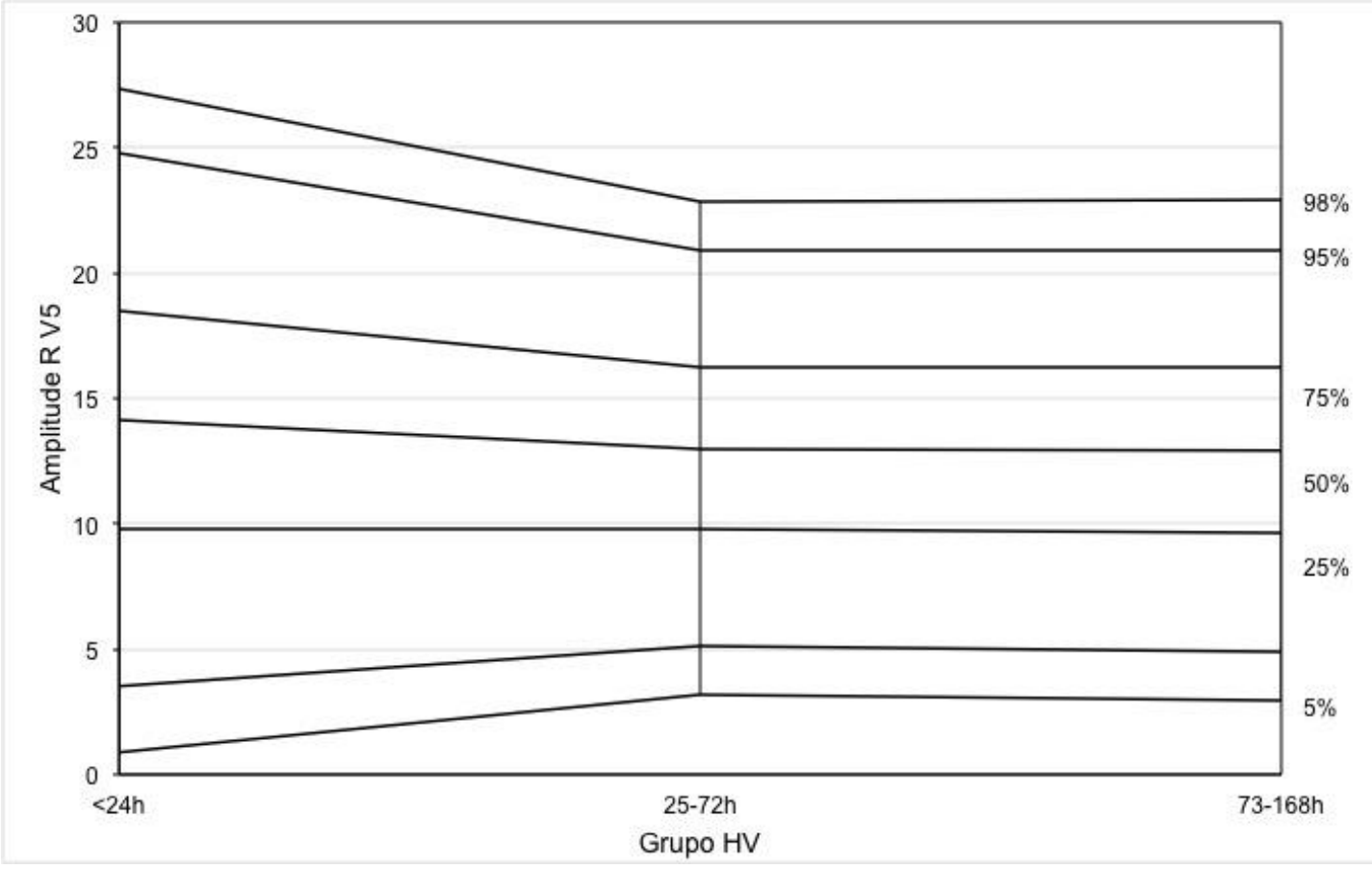

Anexo R. Percentis da amplitude da onda $R$ na derivação $V 6$ versus horas de vida.

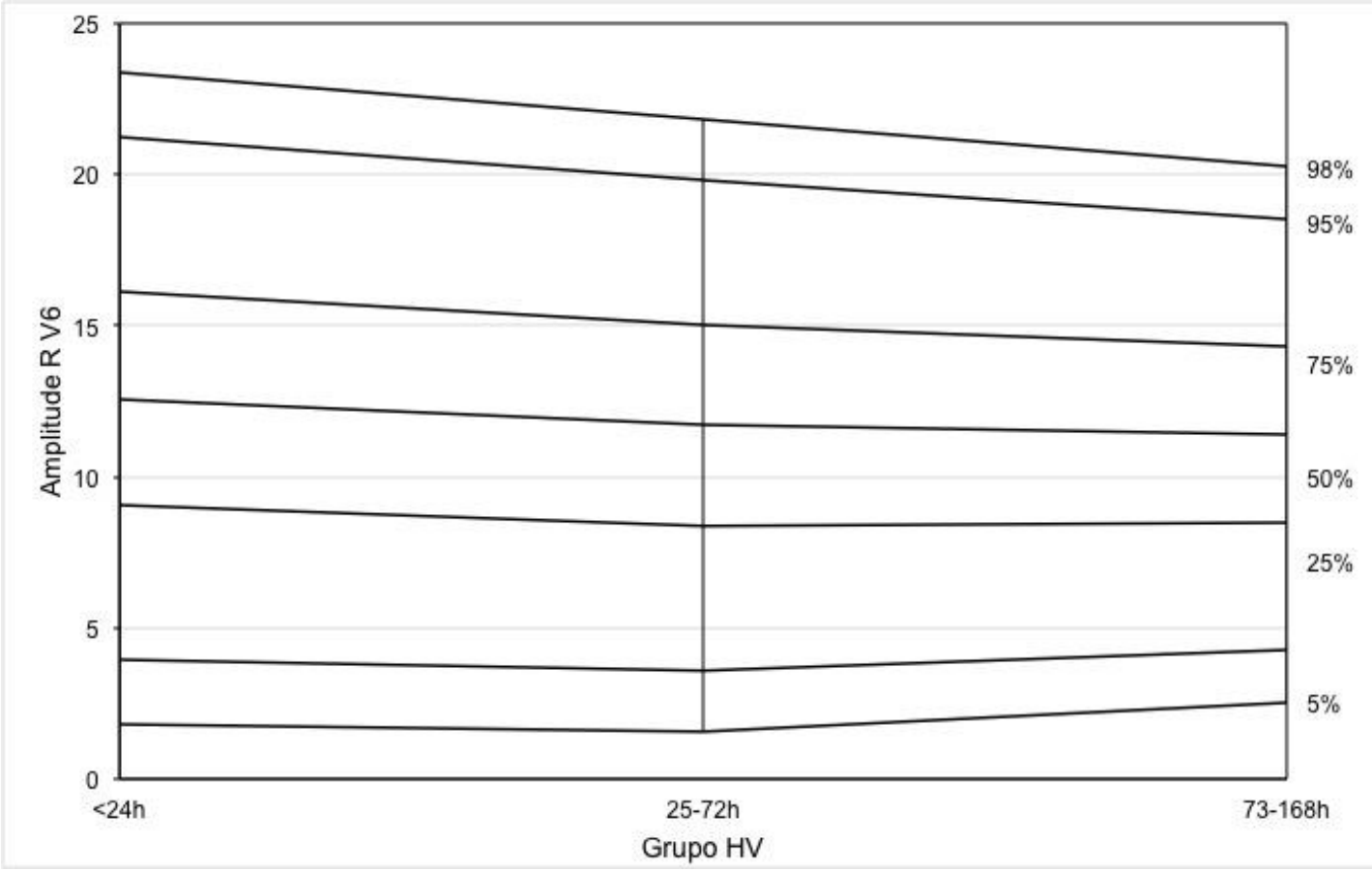


Anexo S. Percentis da amplitude da onda S na derivação V1 versus horas de vida.

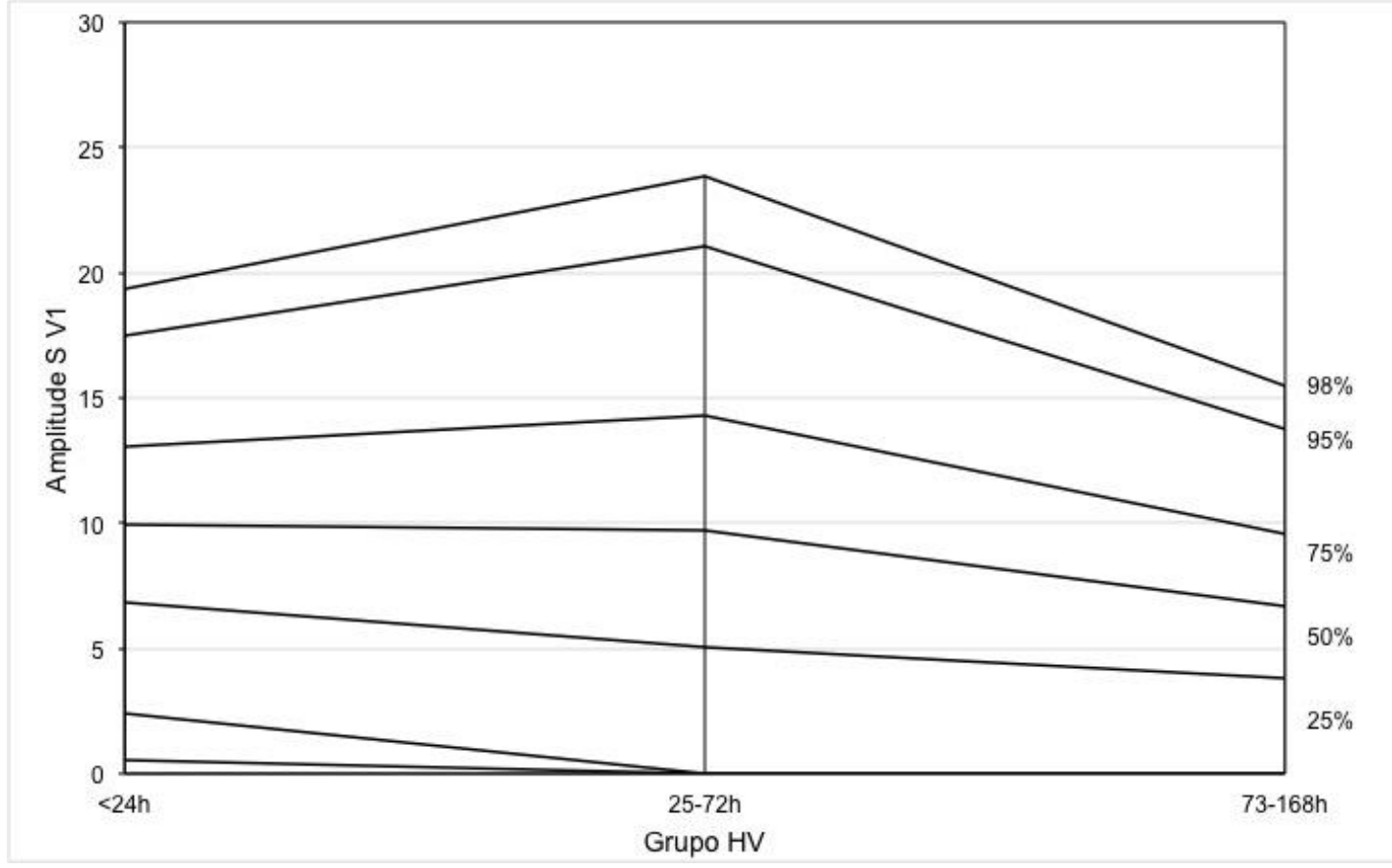

Anexo T. Percentis da amplitude da onda $S$ na derivação V2 versus horas de vida.

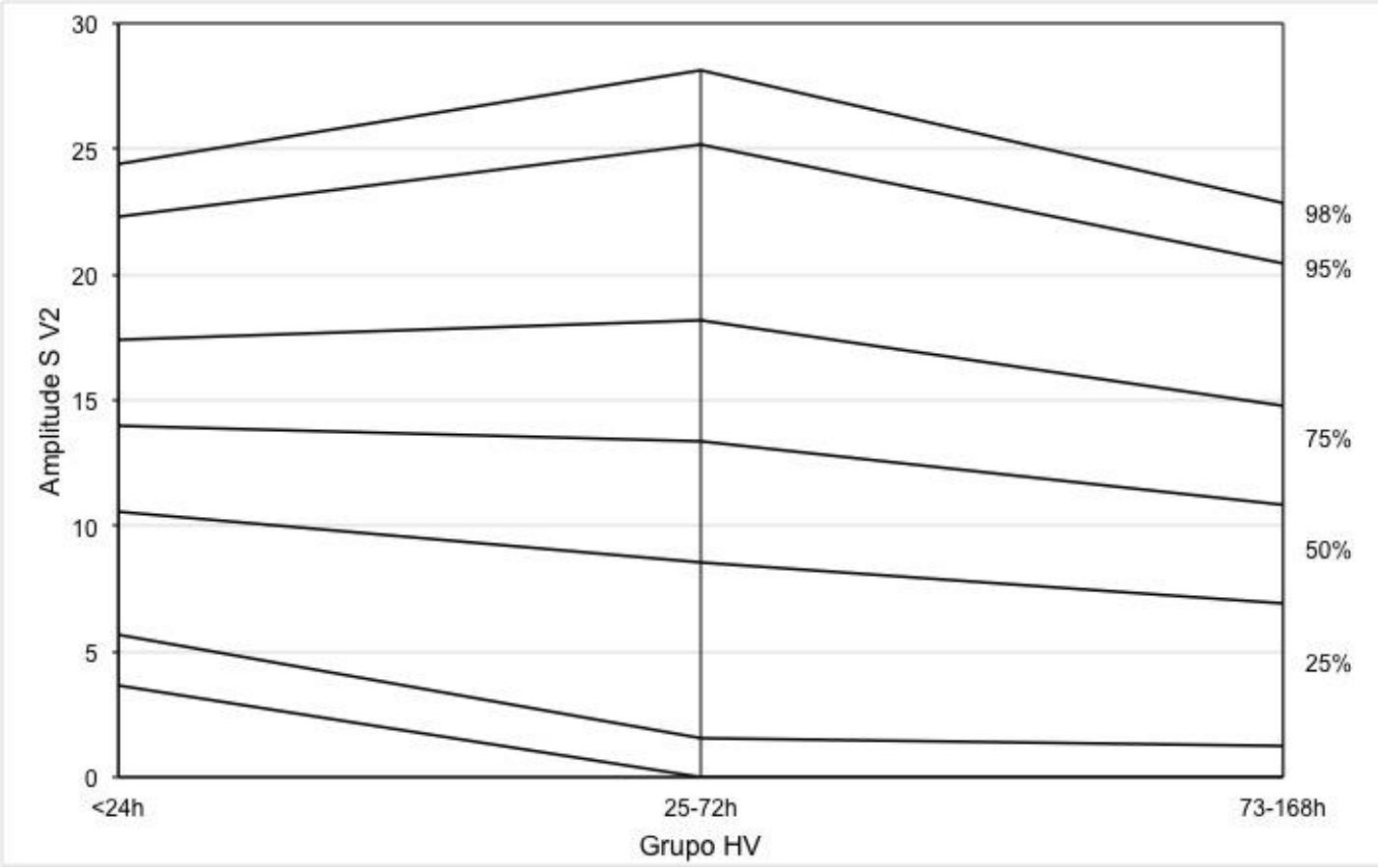


Anexo U. Percentis da amplitude da onda S na derivação V4 versus horas de vida.

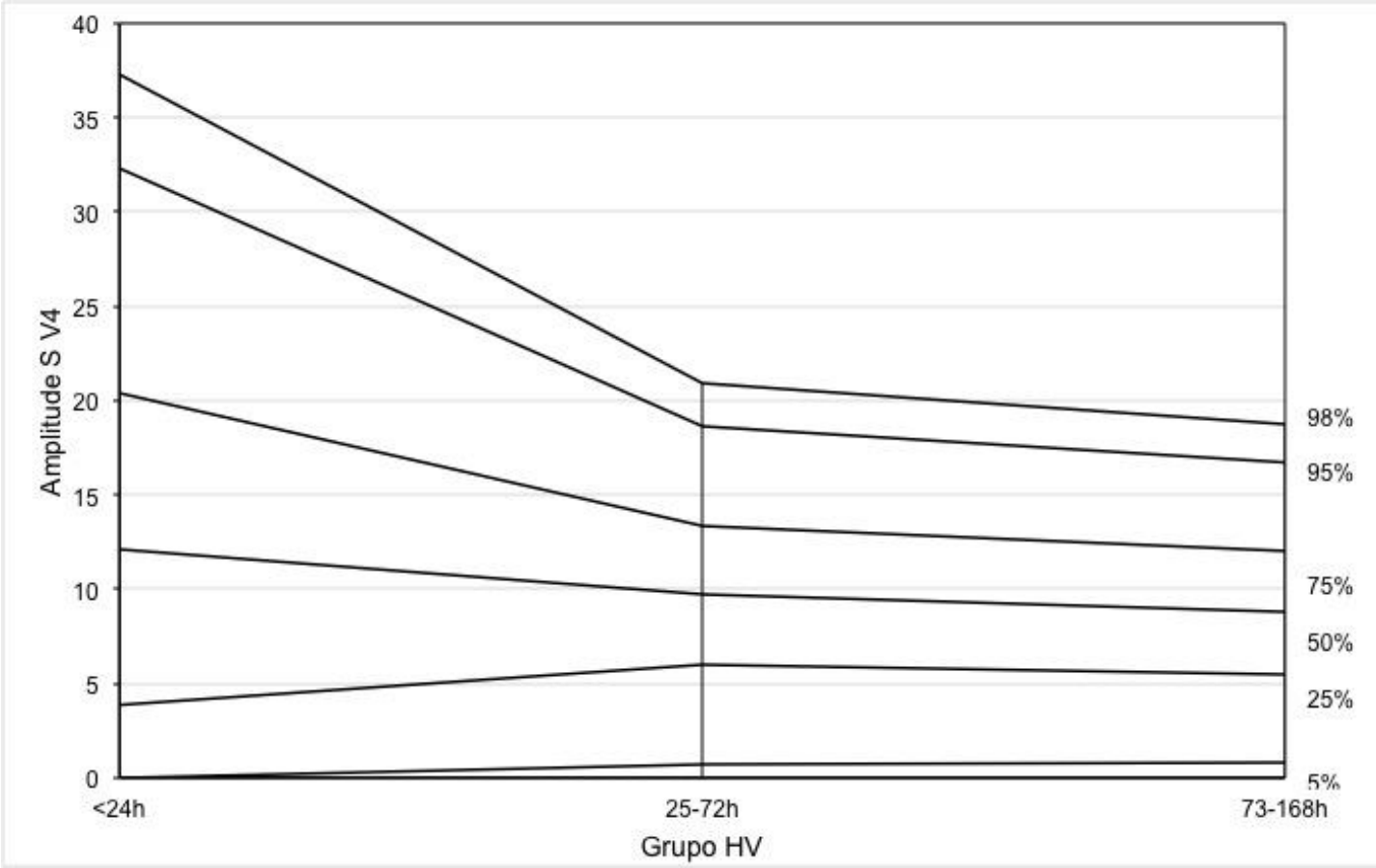

Anexo V. Percentis da amplitude da onda S na derivação V5 versus horas de vida.

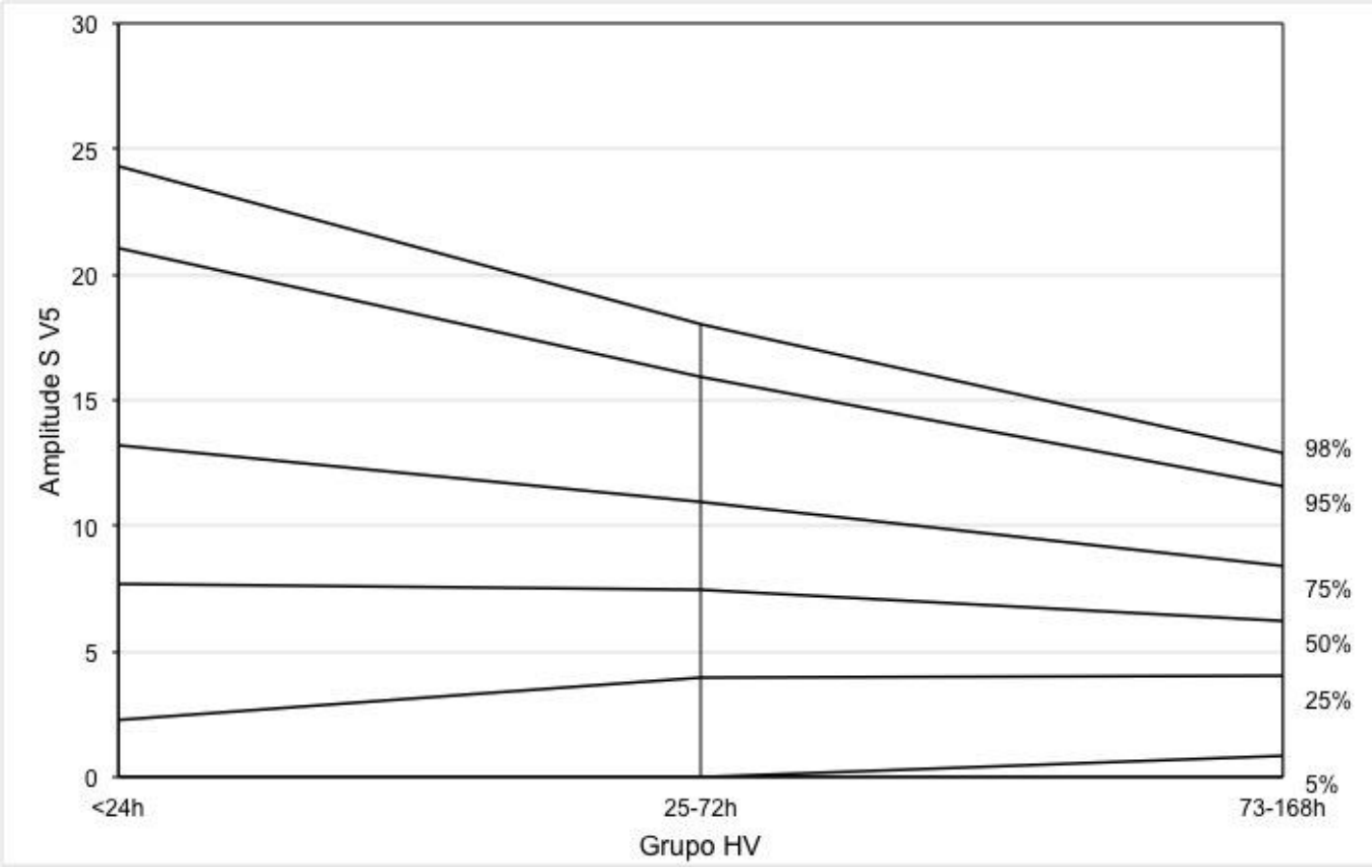


Anexo X. Percentis da amplitude da onda S na derivação V6 versus horas de vida.

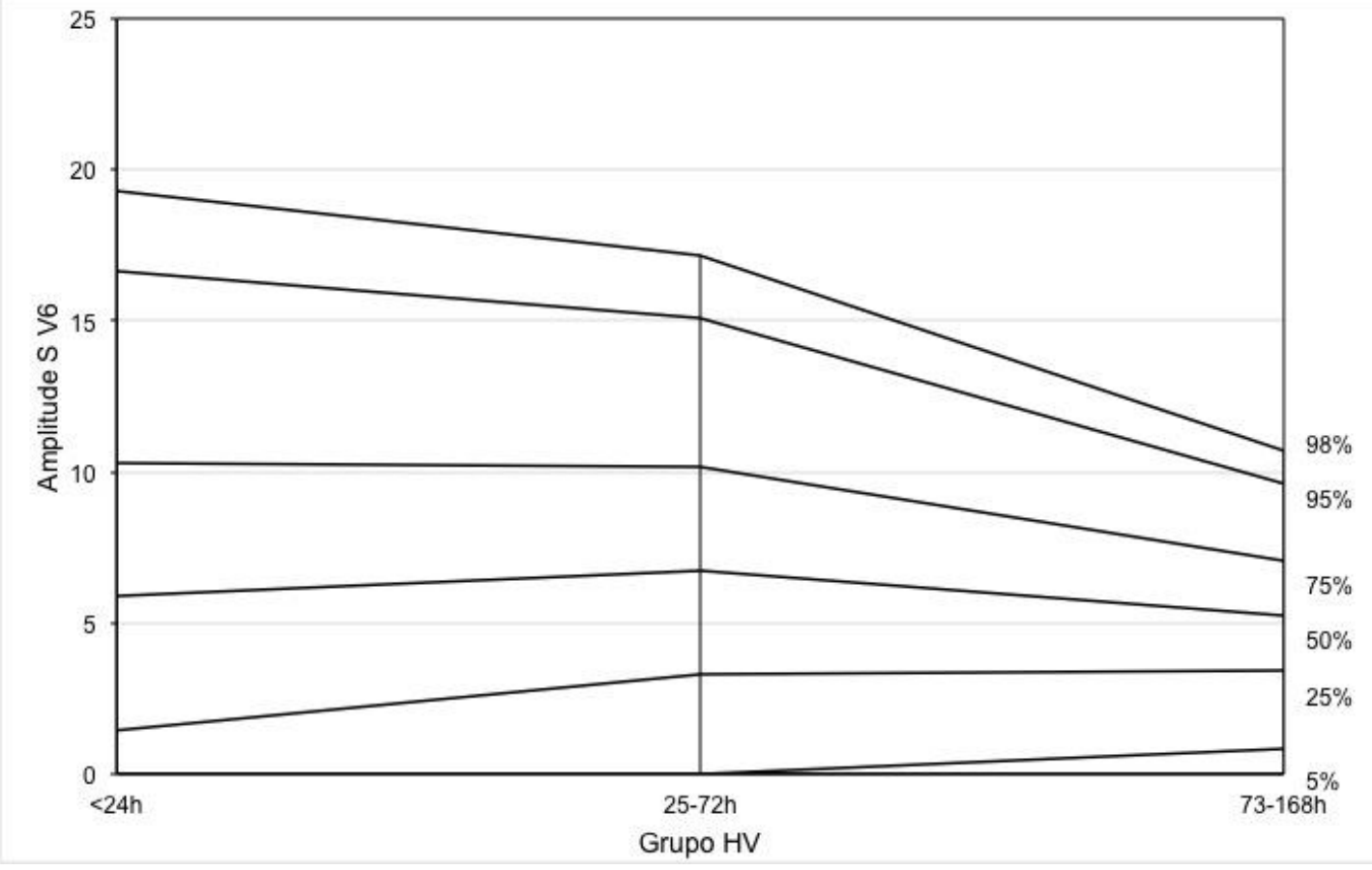

Anexo Z. Percentis da relação das ondas $\mathrm{R} / \mathrm{S}$ na derivação V1 versus horas de vida.

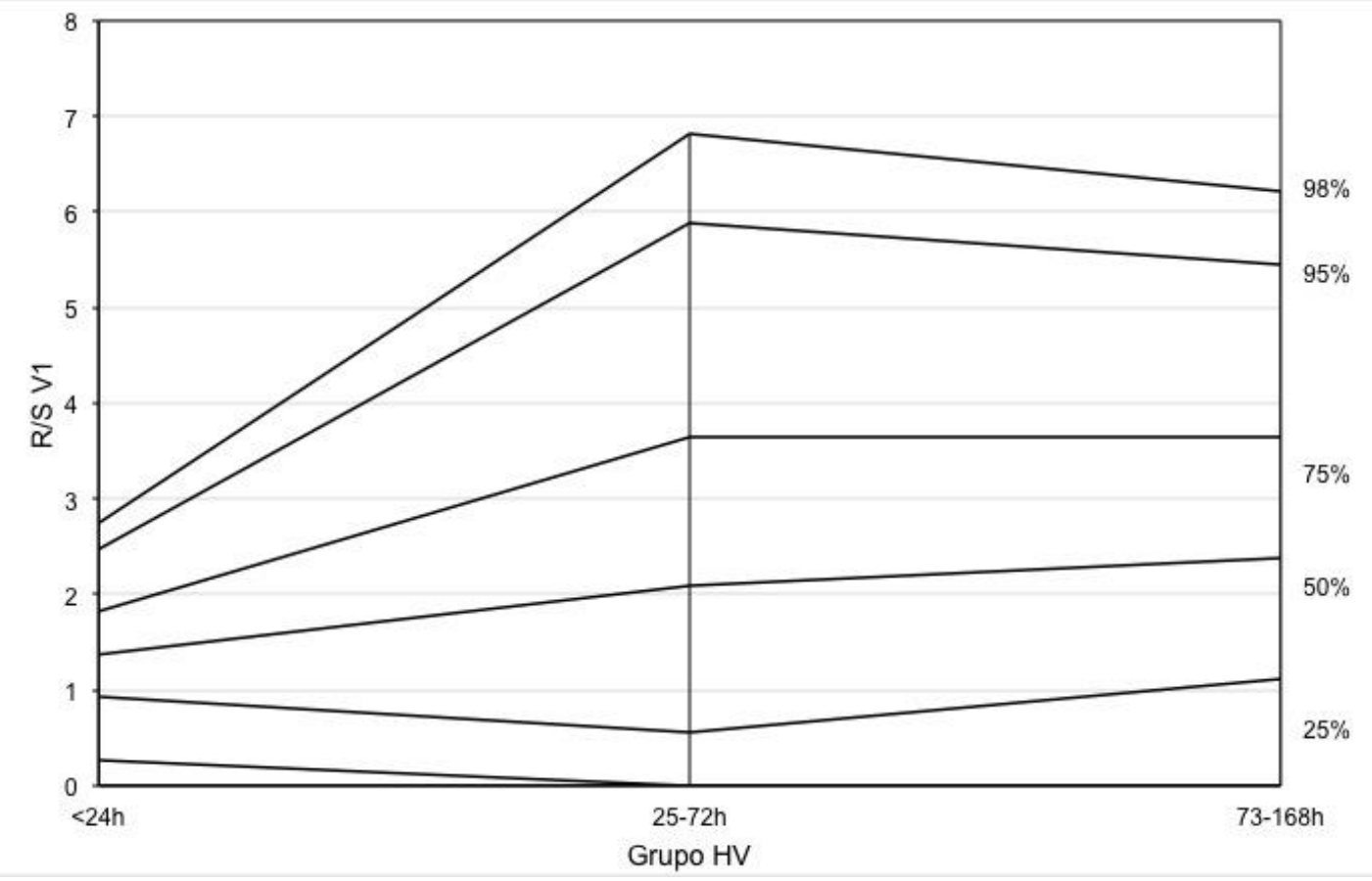


Anexo Aa. Percentis da relação das ondas R/S na derivação V5 versus horas de vida.

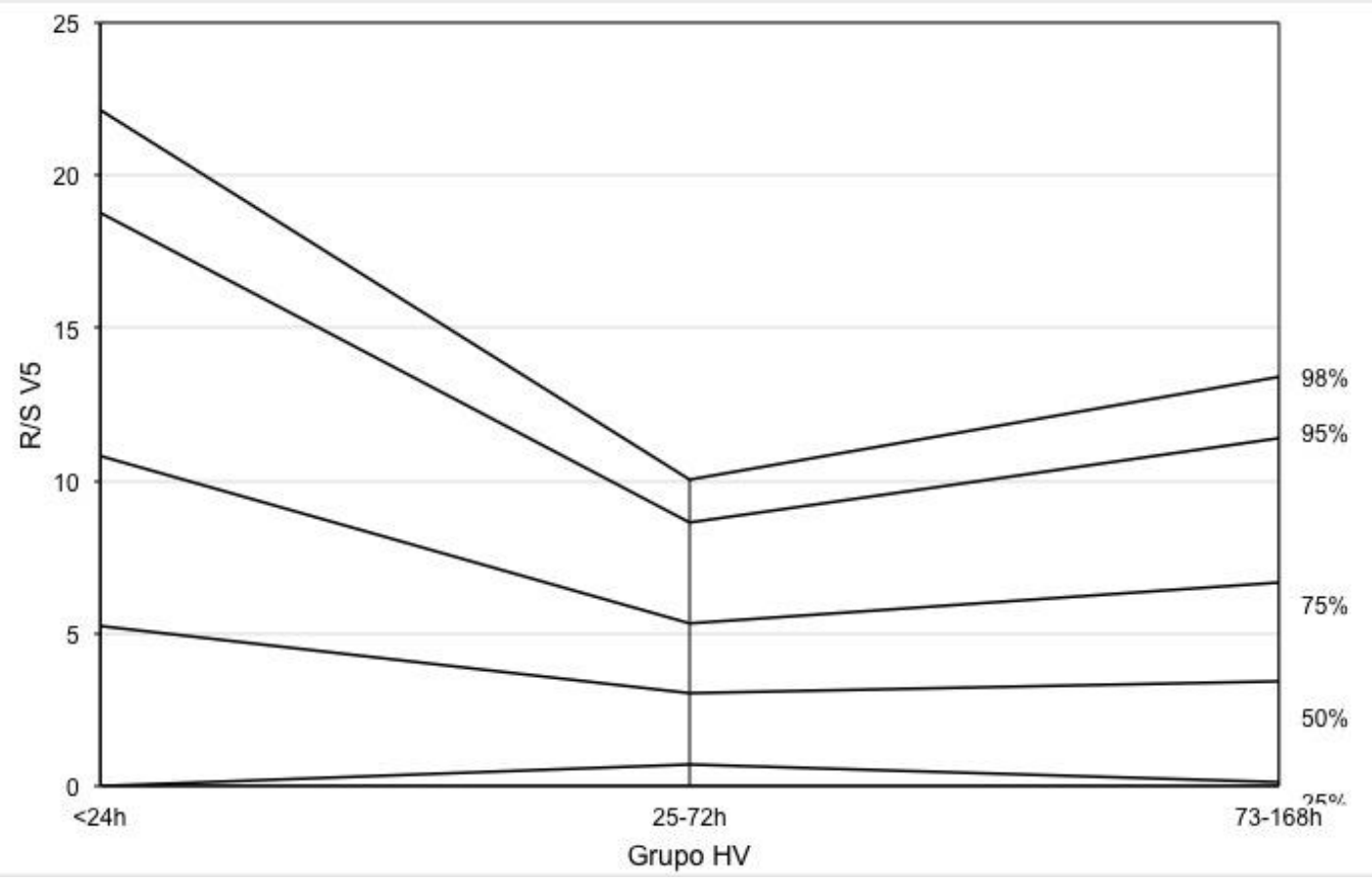

Anexo Ab. Percentis da relação das ondas R/S na derivação V6 versus horas de vida.

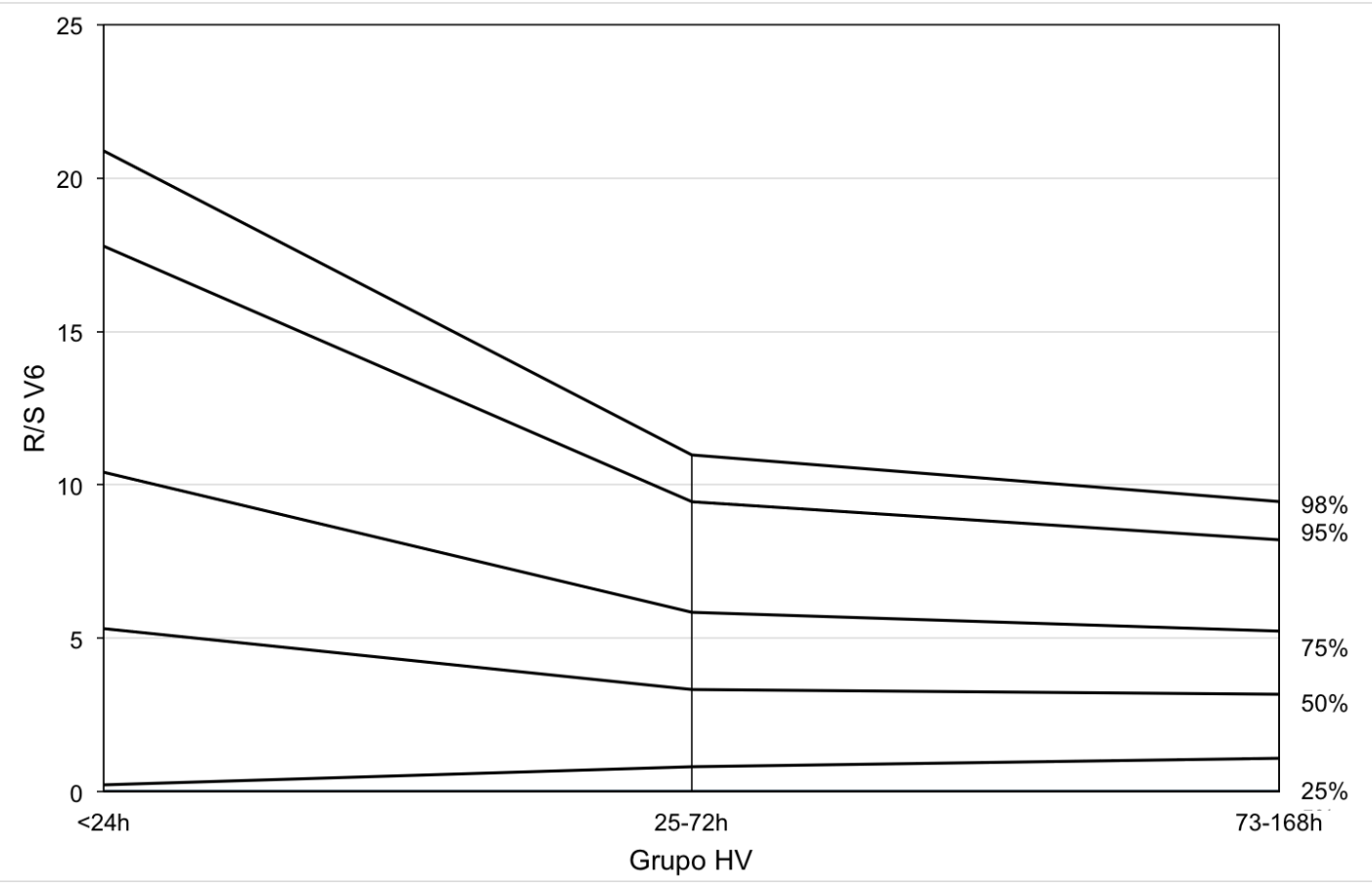


Anexo Ac. Percentis da soma das ondas $\mathrm{R}$ e $\mathrm{S}$ na derivação V2 versus horas de vida.

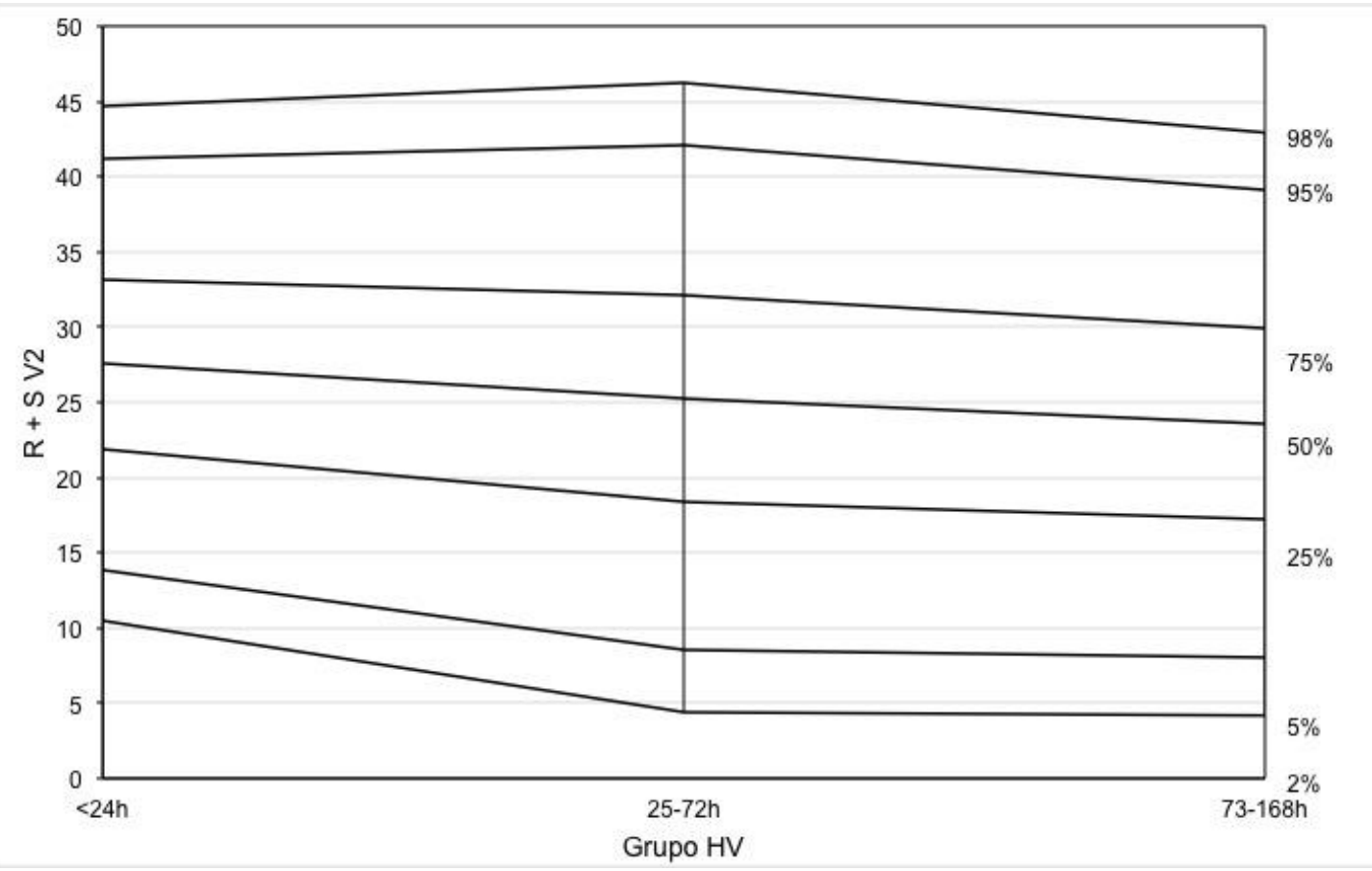

Anexo Ad. Percentis da soma das ondas $\mathrm{R}$ e $\mathrm{S}$ na derivação $\mathrm{V} 4$ versus horas de vida.

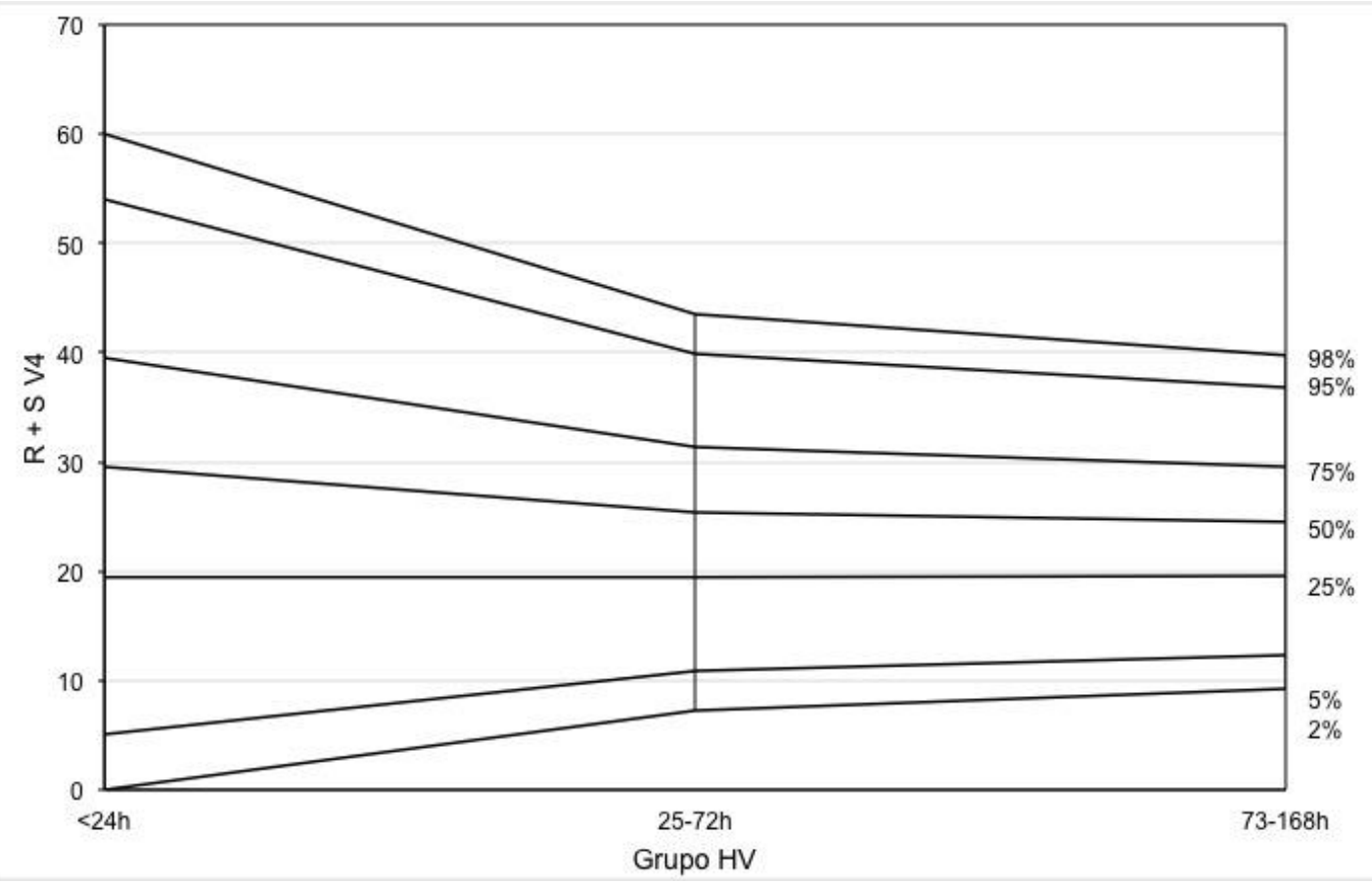


Anexo Ae. Percentis da soma das ondas $S$ na derivação $V 2$ e $R$ na derivação V5 versus horas de vida.

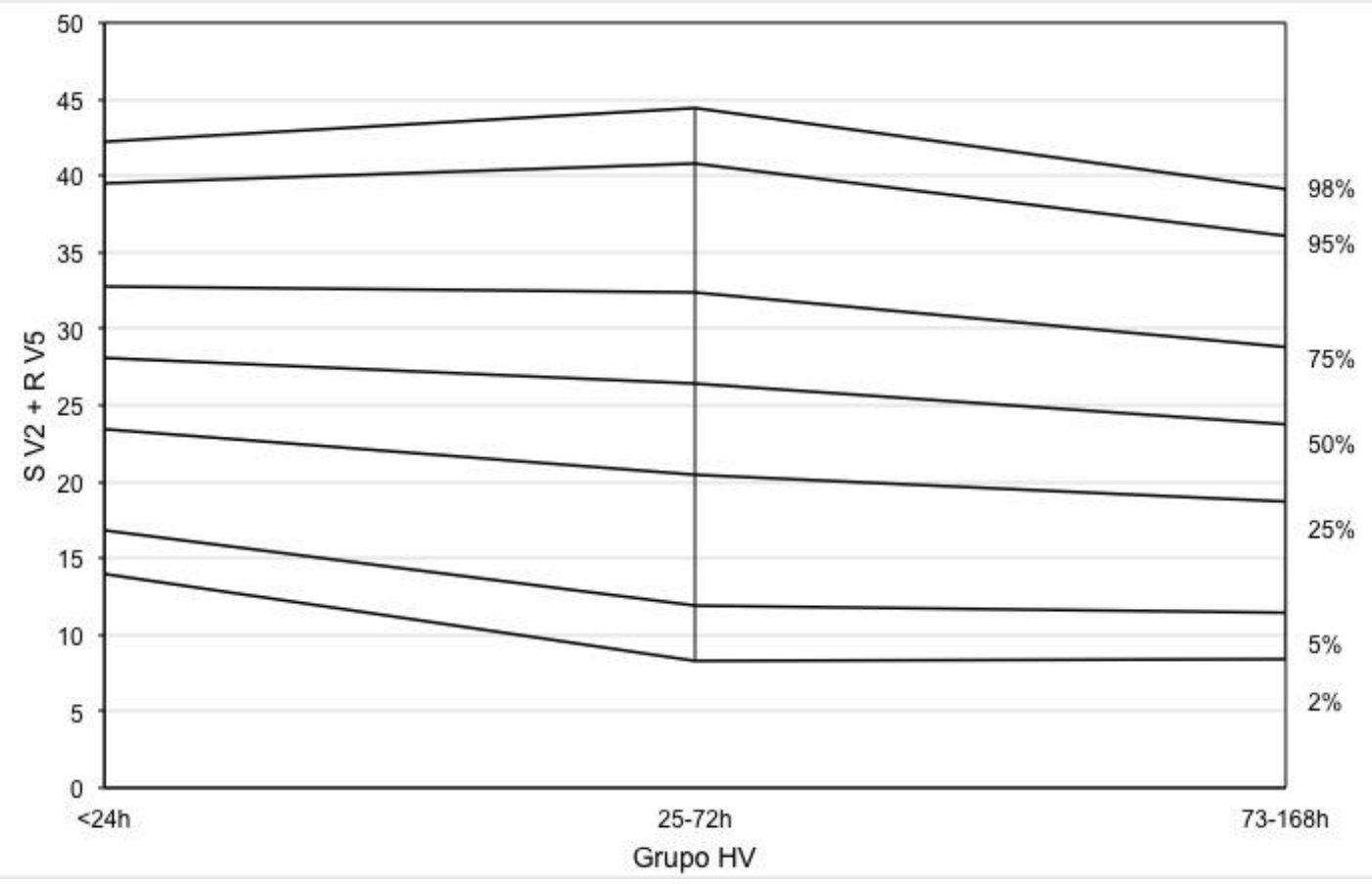

Anexo Af. Percentis da soma das ondas $S$ na derivação V1 e $R$ na derivação V6 versus horas de vida.

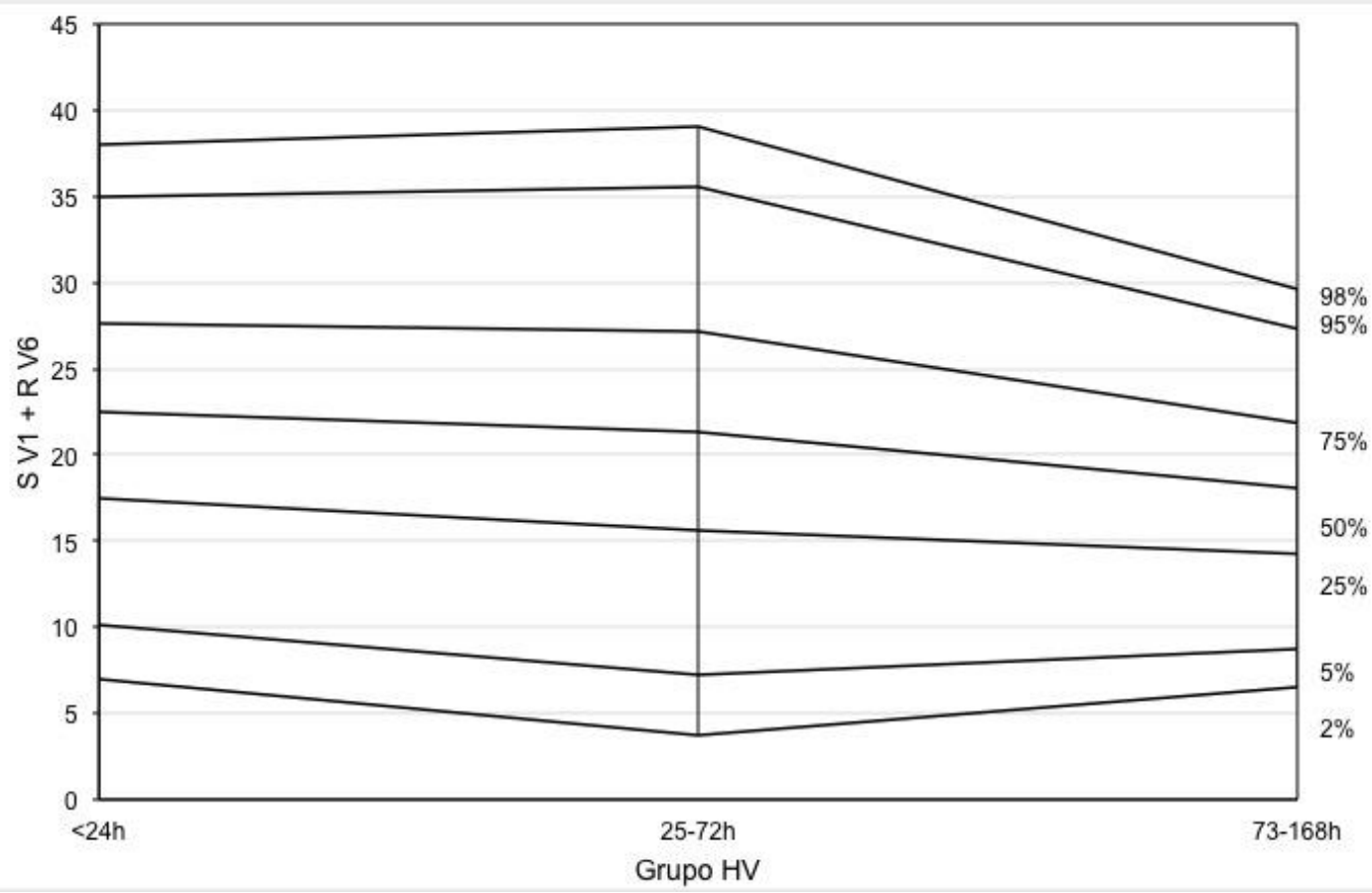


Anexo Ag. Percentis da duração do complexo QRS na derivação V5 versus horas de vida.

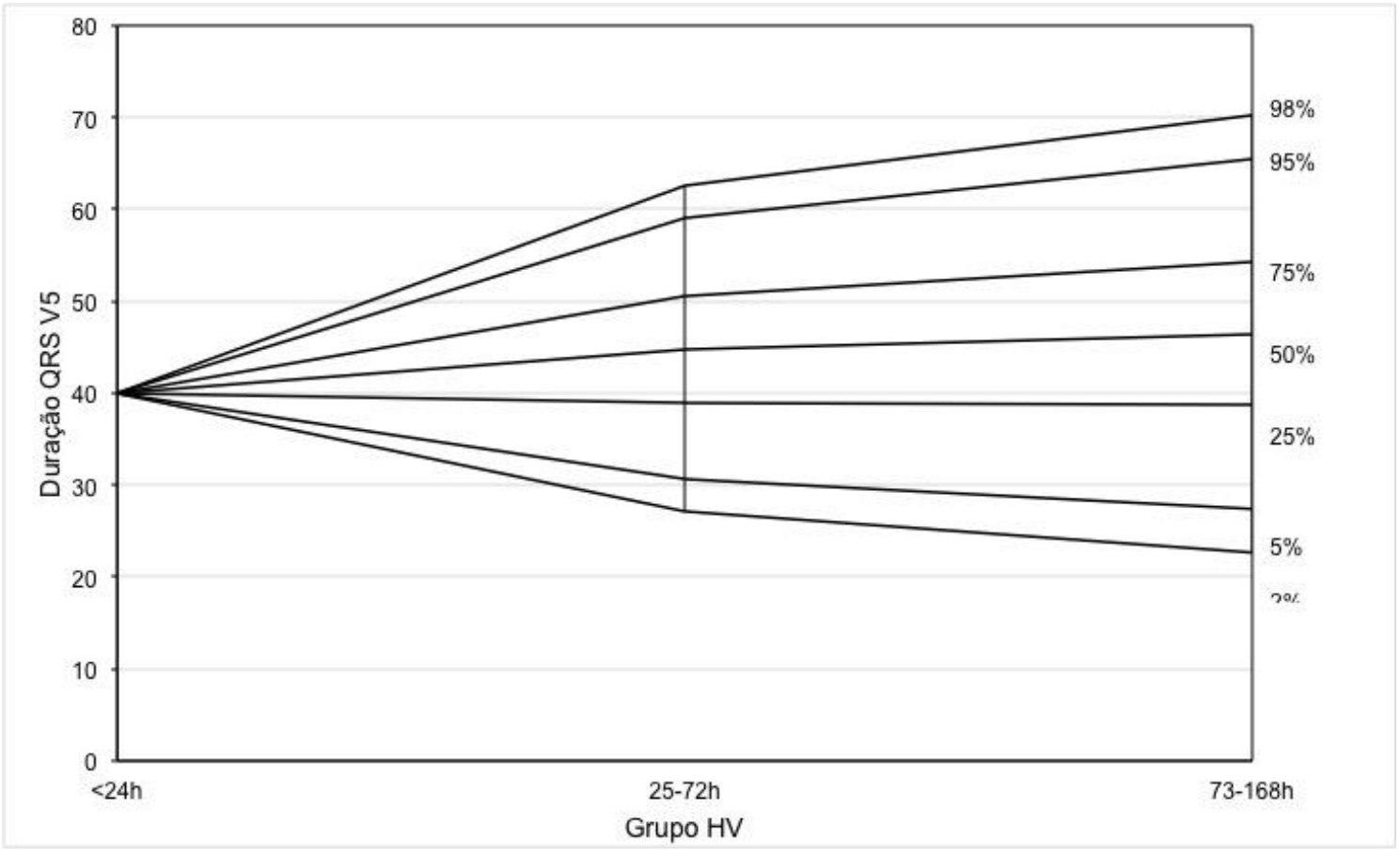


Anexo Ah. Descrição dos parâmetros eletrocardiográficos segundo DM da mãe e resultado dos testes comparativos.

\begin{tabular}{|c|c|c|c|c|c|}
\hline \multirow{2}{*}{ Variável } & \multicolumn{4}{|c|}{ DM mãe } & \multirow{2}{*}{$p$} \\
\hline & Não & DM1 & DM2 & DMG & \\
\hline FC & & & & & 0,002 \\
\hline $\begin{array}{l}\text { média } \pm \text { DP } \\
\text { mediana } \\
\text { (mín.; máx.) }\end{array}$ & $\begin{array}{c}124,8 \pm 15,4 \\
122,5 \\
(87 ; 164)\end{array}$ & $\begin{array}{c}118,7 \pm 8,6 \\
118 \\
(105 ; 138)\end{array}$ & $\begin{array}{c}140,9 \pm 18 \\
144 \\
(113 ; 162)\end{array}$ & $\begin{array}{c}121,4 \pm 17,4 \\
116 \\
(101 ; 155)\end{array}$ & \\
\hline Ampl P DII & & & & & 0,006 \\
\hline $\begin{array}{l}\text { média } \pm \text { DP } \\
\text { mediana } \\
\text { (mín.; máx.) }\end{array}$ & $\begin{array}{c}1,23 \pm 0,43 \\
1 \\
(0,5 ; 2)\end{array}$ & $\begin{array}{c}1,20 \pm 0,48 \\
1,25 \\
(0,5 ; 2)\end{array}$ & $\begin{array}{c}1,69 \pm 0,38 \\
2 \\
(1 ; 2)\end{array}$ & $\begin{array}{c}1,31 \pm 0,38 \\
1 \\
(1 ; 2)\end{array}$ & \\
\hline QT V2 & & & & & 0,033 \\
\hline $\begin{array}{l}\text { média } \pm \text { DP } \\
\text { mediana } \\
\text { (mín.; máx.) }\end{array}$ & $\begin{array}{c}289,0 \pm 47,1 \\
280 \\
(220 ; 400)\end{array}$ & $\begin{array}{c}284,0 \pm 45 \\
280 \\
(220 ; 360)\end{array}$ & $\begin{array}{c}255,4 \pm 47,7 \\
240 \\
(200 ; 360)\end{array}$ & $\begin{array}{c}310,8 \pm 51,4 \\
280 \\
(240 ; 400)\end{array}$ & \\
\hline QTc V2 & & & & & 0,032 \\
\hline $\begin{array}{l}\text { média } \pm \text { DP } \\
\text { mediana } \\
\text { (mín.; máx.) }\end{array}$ & $\begin{array}{c}413,9 \pm 57,4 \\
413,5 \\
(295 ; 546)\end{array}$ & $\begin{array}{c}363,8 \pm 119,3 \\
364 \\
(82 ; 513)\end{array}$ & $\begin{array}{c}386,8 \pm 50,7 \\
378 \\
(307 ; 494)\end{array}$ & $\begin{array}{c}436,9 \pm 47,1 \\
431 \\
(386 ; 537)\end{array}$ & \\
\hline $\begin{array}{l}\text { Orientação T III, } \\
\text { n (\%) }\end{array}$ & & & & & 0,011 \\
\hline Positivo & $45(77,6)$ & $6(60)$ & $5(38,5)$ & $13(100)$ & \\
\hline Negativo & $12(20,7)$ & $4(40)$ & $5(38,5)$ & $0(0)$ & \\
\hline $\begin{array}{l}\text { Plus-Minus } \\
\text { Minus-Plus }\end{array}$ & $\begin{array}{c}0(0) \\
1(1,7)\end{array}$ & $\begin{array}{l}0(0) \\
0(0)\end{array}$ & $\begin{array}{c}1(7,7) \\
2(15,4)\end{array}$ & $\begin{array}{l}0(0) \\
0(0)\end{array}$ & \\
\hline
\end{tabular}

$\mathbf{D M}=$ Diabetes mellitus; DM1 = Diabetes mellitus tipo 1; DM2 = Diabetes mellitus tipo 2; DMG = Diabetes mellitus gestacional; $\mathbf{F C}=$ frequência cardíaca; Ampl = amplitude. 
Anexo Ai. Resultado das comparações entre as categorias de DM materno para os parâmetros que apresentaram diferenças.

\begin{tabular}{lcccccc}
\hline \multirow{2}{*}{ Variável } & \multirow{2}{*}{ Comparação } & $\begin{array}{c}\text { Diferença } \\
\text { média }\end{array}$ & $\begin{array}{c}\text { Erro } \\
\text { padrão }\end{array}$ & $\boldsymbol{p}$ & \multicolumn{2}{c}{ IC (95\%) } \\
\cline { 6 - 8 } & Não - DM1 & 6,15 & 5,32 & $>0,999$ & $-8,20$ & 20,49 \\
\multirow{4}{*}{ FC } & Não - DM2 & $-16,00$ & 4,76 & $\mathbf{0 , 0 0 7}$ & $-28,85$ & $-3,15$ \\
& Não - DMG & 3,46 & 4,76 & $>0,999$ & $-9,39$ & 16,31 \\
& DM1 - DM2 & $-22,15$ & 6,53 & $\mathbf{0 , 0 0 6}$ & $-39,76$ & $-4,53$ \\
& DM1 - DMG & $-2,69$ & 6,53 & $>0,999$ & $-20,30$ & 14,93 \\
& DM2 - DMG & 19,46 & 6,09 & $\mathbf{0 , 0 1 2}$ & 3,03 & 35,89 \\
\hline \multirow{4}{*}{ Ampl P DII } & Não - DM1 & 0,03 & 0,15 & $>0,999$ & $-0,36$ & 0,43 \\
& Não - DM2 & $-0,46$ & 0,13 & $\mathbf{0 , 0 0 4}$ & $-0,81$ & $-0,11$ \\
& Não - DMG & $-0,07$ & 0,13 & $>0,999$ & $-0,43$ & 0,28 \\
& DM1 - DM2 & $-0,49$ & 0,18 & $\mathbf{0 , 0 4 3}$ & $-0,97$ & $-0,01$ \\
\multirow{3}{*}{ QT V2 } & DM1 - DMG & $-0,11$ & 0,18 & $>0,999$ & $-0,59$ & 0,37 \\
& DM2 - DMG & 0,38 & 0,17 & 0,140 & $-0,07$ & 0,83 \\
\hline & Não - DM1 & 4,97 & 16,29 & $>0,999$ & $-38,99$ & 48,92 \\
& Não - DM2 & 33,58 & 14,60 & 0,143 & $-5,81$ & 72,97 \\
& Não - DMG & $-21,80$ & 14,60 & 0,833 & $-61,20$ & 17,59 \\
& DM1 - DM2 & 28,62 & 20,02 & 0,938 & $-25,38$ & 82,61 \\
& DM1 - DMG & $-26,77$ & 20,02 & $>0,999$ & $-80,77$ & 27,23 \\
\hline \multirow{4}{*}{ QTc V2 } & DM2 - DMG & $-55,39$ & 18,67 & $\mathbf{0 , 0 2 3}$ & $-105,74$ & $-5,03$ \\
& Não - DM1 & 50,11 & 22,06 & 0,153 & $-9,39$ & 109,61 \\
& Não - DM2 & 27,15 & 19,77 & $>0,999$ & $-26,18$ & 80,47 \\
& Não - DMG & $-22,93$ & 19,77 & $>0,999$ & $-76,26$ & 30,39 \\
& DM1 - DM2 & $-22,97$ & 27,09 & $>0,999$ & $-96,06$ & 50,12 \\
\hline DM1
\end{tabular}

DM1 = Diabetes mellitus tipo 1; DM2 = Diabetes mellitus tipo 2; DMG = Diabetes mellitus gestacional; $\mathbf{F C}=$ frequência cardíaca; $\mathbf{A m p l}=$ amplitude. 


\section{REFERÊNCIAS BIBLIOGRÁFICAS}

1. Hastreitter AR, Abella JB. The electrocardiogram in the newborn period. I. The normal infant. J Pediatr. 1971; 78(1): 146-156. Review.

2. Davignon A, Rautaharju P, Boisselle E, Soumis F, Mégélas $M$, Choguette A. Normal ECG standards for infants and children. Pediatr Cardiol. 1980; 1:123-131.

3. Bensley JG, Matteo R, Harding R, Black MJ. The effects of preterm birth and its antecedents on the cardiovascular system. Acta Obstet Gynecol Scand. 2016; 95(6): 652-63.

4. Pastore CA, Pinho JA, Pinho C, Samesima N, Pereira Filho HG, Kruse JC, Paixão A, Pérez-Riera AR, Ribeiro AL, Oliveira CA, Gomes Cl, Kaiser E, Galvão F, Darrieux FC, França FF, Feitosa Filho G, Germiniani H, Aziz JL, Leal MG, Molina M, Oliveira NM, Oliveira PA, Sanches PC, Almeida RM, Barbosa R, Teixeira RA, Douglas RA, Gundim RS, Atanes SM. III Diretrizes da Sociedade Brasileira de Cardiologia Sobre Análise e Emissão de Laudos Eletrocardiográficos. Arq Bras Cardiol. 2016; 106 (4 Suppl 1): 1-23.

5. Rijnbeek PR, Witsenburg M, Schrama E, Hess J, Kors JA. New normal limits for the paediatric electrocardiogram. Eur Heart J. 2001; 22(8): 70211.

6. Palhares DMF, Marcolino MS, Santos TMM, Silva, JLP, Gomes PR, Ribeiro LB, Macfarlane PW, Ribeiro ALP. Normal limits of the 
electrochardiogram derives from a large database of brazilian primary care patients. BMC Cardiovasc Disord. 2017; 17(1): 152.

7. Pike JI, Krishnan A, Kaltman J, Donofrio MT. Fetal and neonatal atrial arrhythmias: an association with maternal diabetes and neonatal macrossomia. Prenat Diagn. 2013; 33(12): 1152-7.

8. Arslan D, Guvenc O, Cimen D, Ulu H, Oran B. Prolonged QT dispersion in the infants of diabetic mothers. Pediatr Cardiol. 2014; 35(6): 1052-6.

9. Kardasevic M, KardaseviC A. The importance of heart murmur in the neonatal period and justification of echocardiographic review. Med Arch. $2014 ; 68(4): 282-4$.

10. www.datasus.gov.br

11. Pimenta MS, Calil VMLT, Krebs VLJ. Profile of the congenital malformations in a Neonatal Intensive Care Unit (NICU) at a tertiary care reference University Hospital in Brazil. Rev Med. 2010; 89(1): 50-6.

12. Page OC, Garlan J, Stephens JW, Hare RL. The eletrocardiogram in infants of diabetic mothers. J Pediatr. 1960; 56: 66-74.

13. Mirvis DM, Goldberger AL. Electrocardiography. In Braunwald E, Zipes DP, Libby P (eds): Heart Disease. A Textbook of Cardiovascular Medicine. $6^{\text {th }}$ ed. Philadelphia, PA. Saunders, 2001, p. 82-128.

14. Khan GM. A new electrode placement method for obtaining 12-lead ECGs. Open Heart. 2015; 2(1): 1-10.

15. Lai WW, Geva T, Shirali GS, Frommelt PC, Humes RA, Brook MM, Pignateli RH, Rychik J. Guidelines and standards for performande of a pediatric echocardiogram: a report from the task force of the pediatric 
council of American Society of Echocardiography. $J A m$ Soc Echocardiogr. 2006; 19: 1413-30.

16.Kampmann C, Wiethoff CM, Wenzel A, Stolz G, Betancor M, Wippermann CF, Huth RG, Habermehl P, Knuf M, Emschermann T, Stopfkuchen $\mathrm{H}$. Normal values of $\mathrm{M}$ mode echocardiographic measurements of more than 2000 healthy infants and children in central Europe. Heart. 2000; 83(6): 667-72.

17. Kirkwood BR, Sterne JAC. Essential medical statistics. $2^{\text {nd }}$ ed. Massachusetts, USA. Blackwell Science, 2006, p. 502.

18. Neter J, Kutner MH, Nachtsheim CJ, Wasserman W. Applied Linear Statistical Models. $4^{\text {th }}$ ed. Ilinois, USA. Richard D. Irwing, 1996, p. 1408.

19.WORLD HEALTH ORGANIZATION. WHO statement on Caesarean section rates. 2015 .

20. Doerr, H., Versmold, H., Bidlingmaier, F. et al. Adrenocortical Steroids in Small-for-Gestational-Age Term Infants during the Early Neonatal Period. Pediatr Res. 1989; 25:115-8.

21. Economides D, L, Nicolaides K, H, Linton E, A, Perry L, A, Chard T: Plasma Cortisol and Adrenocorticotropin in Appropriate and Small for Gestational Age Fetuses. Fetal Diagn Ther. 1988; 3:158-64.

22. El-Ganzoury MM, El-Masry SA, El-Farrash RA, Anwar M, Abd Ellatife RZ. Infants of diabetic mothers: echocardiographic measurements and cord blood IGF-I and IGFBP-1. Pediatric Diabetes. 2012; 13: 189-96. 